\title{
1 Variability in cyanobacteria sensitivity \\ 2 to antibiotics and implications for \\ 3 Environmental Risk Assessment
}

4 Gareth Le Page , Lina Gunnarsson , Maciej Trznadel , Kyle C. A. Wedgwood , Virgile

5 Baudrot ${ }^{c, d}$ Jason Snape ${ }^{e, f}$, Charles R. Tyler

6 Biosciences, College of Life and Environmental Sciences, University of Exeter, Geoffrey Pope, Stocker Road,

7 Exeter, Devon, EX4 4QD, UK.

8 bCollege of Engineering, Mathematics and Physical Sciences, University of Exeter, Living Systems Institute,

9 Stocker Road, Exeter, Devon, EX4 4QD, UK

cINRA BioSP, 84000 Avignon, France

11 dLaboratoire de Biométrie, Université de Lyon; Université Lyon 1; CNRS; UMR 5558; Bâtiment Gregor Mendel,

12 Mezzanine 43 boulevard du 11 novembre 1918 F-69622 Villeurbanne Cedex, France (present address)

13 e AstraZeneca, Global Safety, Health and Environment, Alderley Park, Macclesfield, Cheshire, SK10 4TF, UK

14 fSchool of Life Sciences, Gibbet Hill Campus, The University of Warwick, Coventry, CV4 7AL

15 Corresponding author: Charles R Tyler. Geoffrey Pope, College of Life and Environmental Sciences, University of 16 Exeter, Exeter, EX4 4QD. C.R.Tyler@exeter.ac.uk 
Abstract

Once released into the environment antibiotics can kill or inhibit the growth of bacteria, and in turn potentially have effects on bacterial community structure and ecosystem function. Environmental risk assessment (ERA) seeks to establish

21 protection limits to minimise chemical impacts on the environment, but recent evidence suggests that the current regulatory approaches for ERA for antibiotics may not be adequate for protecting bacteria that have fundamental roles in ecosystem function. In this study we assess the differences in interspecies sensitivity of eight species of cyanobacteria to seven antibiotics (cefazolin, cefotaxime, ampicillin, sufamethazine, sulfadiazine, azithromycin and erythromycin) with three different modes of action. We found that variability in the sensitivity to these antibiotics between species was dependent on the mode of action and varied by up to 70 times for $\beta$-lactams. Probabilistic analysis using species sensitivity distributions suggest that the current predicted no effect concentration PNEC for the antibiotics may be either over or under protective of cyanobacteria dependent on the species on which it is based and the mode of action of the antibiotic; the PNECs derived for the macrolide antibiotics were over protective but PNECs for $\beta$-lactams were generally under protective. For some geographical locations we identify a significant risk to cyanobacteria populations based upon measured environmental concentrations of selected antibiotics. We conclude that protection limits, as determined according to current regulatory guidance, may not always be protective and might be better derived using SSDs and that including toxicity data for a wider range of (cyano-) bacteria would improve confidence for the ERA of antibiotics. 


\section{Keywords:}

42 Antibiotics; Antimicrobial resistance; Environmental risk assessment;

43 Pharmaceuticals; Species sensitivity distribution; Predicted No Effect 44 Concentration 


\section{Introduction}

46 Antibiotics are designed to kill or inhibit the growth of bacteria and are

47 fundamental in the treatment of pathogens in human and veterinary healthcare.

48 Following their release into the environment however, non-target bacteria may

49 be affected and the vital ecosystem services they facilitate may be disrupted as a

50 consequence, which include primary productivity, nutrient cycling and

51 contaminant degradation (Dopheide et al., 2015; Grenni et al., 2018; Kümmerer,

52 2009). Aquatic ecosystems are especially at risk due to the concentrations of

53 antibiotic inputs received from manufacturing plants and hospital effluents,

54 wastewater treatment plants (WWTP), aquaculture, and run-off from agriculture

55 (Batt et al., 2007; Brown et al., 2006; Cabello, 2006; Jaimes-Correa et al., 2015;

56 Larsson, 2014; Larsson et al., 2007; Li et al., 2008; Liu et al., 2017; Watkinson et

57 al., 2009). The European regulatory environmental risk assessment (ERA) for

58 antibiotics aims to establish protection limits that prevent "risk of undesirable

59 effects on the environment" (EC, 2001), but the effectiveness of the current

60 approach to do so has been questioned (Agerstrand et al., 2015; Brandt et al.,

61 2015; Le Page et al., 2017). In addition, many antibiotics lack data for

62 environmental bacteria due to the regulatory requirement for ERA testing only

63 coming into force in 2006; before which most antibiotics had already been

64 approved (Le Page et al. 2017). Consequently, there is an urgent need to assess

65 whether the protection limits currently derived according to the current ERA

66 guideline for antibiotics are able to protect against undesirable effects on the

67 environment. 
69 In the European ERA for human medicinal products and the VICH guidelines for 70 veterinary antibiotics, protection limits for pharmaceuticals, including 71 antibiotics, are represented by a predicted no effect concentration (PNEC). This 72 is calculated by applying an assessment factor (AF) of 10 to the lowest no 73 observed effect concentration (NOEC) following testing upon a cyanobacteria 74 (green algae when not an antibiotic), invertebrate, fish and an activated sludge 75 respiration inhibition test (ASRIT); i.e the PNEC is calculated by dividing the 76 lowest NOEC by 10 . The ASRIT however, is not sensitive to antibiotics 77 (Kümmerer, 2009; Le Page et al., 2017) and consequently only a single species of 78 cyanobacteria represents all bacterial diversity in an antibiotic ERA that also 79 measures a single functional endpoint: primary productivity. Additionally, most 80 tests use either Anabaena flos-aquae (particularly in the case of regulatory 81 studies) or Microcystis aeruginosa, providing a limited understanding of 82 cyanobacteria interspecies sensitivity. In a revised version of the EMA guidance 83 for ERA that is currently under consultation, however, it is advocated that two 84 cyanobacteria species should be tested and fish are only tested when the 85 pharmaceutical targets are present. The AF is applied to account for uncertainty 86 due to interspecies variability and the extrapolation from controlled laboratory 87 studies to the field. But the application of an AF of 10 for antibiotics is 88 unsupported by experimental data and evidence shows that in some cases 89 interspecies bacterial sensitivity may exceed this by several orders of magnitude 90 (Chapman et al., 1998; Le Page et al., 2017). Consequently, there may be cases 91 where the PNEC is not protective of all species in the environment. Moreover, a 92 PNEC calculated this way has two potential drawbacks: firstly, the NOEC has 93 been heavily criticised due to its dependence on the design of the experiment 
conducted to derive it (Green et al., 2013) and secondly, because it uses only a single effect value (the NOEC); quantification of the uncertainty around the PNEC is not determined (Chapman et al., 1998).

A second approach for establishing protection limits that overcomes some of the problems associated with the current PNEC approach is through the construction of a species sensitivity distribution (SSD). A SSD is a probability model of interspecies variability across a toxicity endpoint following chemical exposure (e.g. NOEC or $\mathrm{EC}_{\mathrm{x}}$ ) and it allows prediction of the proportion of species affected at any concentration for the species group modelled (Aldenberg et al., 103 2001; Belanger et al., 2017; Wheeler et al., 2002). SSDs are more commonly used for higher tier ERA in plant protection product regulations (EFSA, 2013) or in the Water Framework Directive (European Commission Joint Research Centre, 2003). The protection limit most often derived from a SSD is the hazardous concentration that affects no more than $5 \%$ of species (HC5), although it has

108 been suggested that the lower 95\% confidence limit of the HC5 (HC52.5\%) should 109 be used to ensure a truly protective limit (Verdonck et al., 2001; Wheeler et al., 110 2002). This lower, more protective limit, however, will have more statistical 111 uncertainty. An AF of less than 10 is sometimes applied depending on the 112 specific regulations and quality/quantity of the data on which the SSD is based 113 (EFSA, 2013).

114 In the past SSDs have been criticised for being ecologically unrealistic and for a 115 lack of statistical robustness but recent advances allow for the mitigation of 116 some of these concerns (Forbes and Calow, 2002; Kon Kam King et al., 2015; Kon 117 Kam King et al., 2014). Importantly, SSDs are influenced by the quality and 

mode of action and the even representation of the taxonomic groups of interest.

120 Where previously a sample size of 10-15 species was required for a robust 121 analysis (TGD, 2003), newer protocols that use bootstrap regression and the 122

131 It is not uncommon for the measured environmental concentrations (MECs) of

number of data included, as well as the choice of taxa, their sensitivity to the incorporation of censored data now allow for the computation of reliable statistics from a limited dataset ( $<10$ data points) (Kon Kam King et al., 2014; Wheeler et al., 2002). Fewer species therefore are arguably required to reliably model the lower tail of the SSD (comprising the most sensitive species) from which a protection limit could be derived, providing they are all known to be sensitive to the mode of action (MoA) of the chemical. This is because the SSD focuses upon the species most at risk and the distribution will not be impacted by non-sensitive species or taxonomic clades (Schmitt-Jansen et al., 2008; Segner, 2011).

antibiotics to exceed the PNEC in the environment, especially in WWTP, hospital and manufacturing effluents (Batt et al., 2007; Brown et al., 2006; Jaimes-Correa et al., 2015; Larsson, 2014; Larsson et al., 2007; Li et al., 2008; Watkinson et al., 2009). In these cases it is likely that there is a risk to bacterial communities and the ecosystem functions that they provide. By considering these MECs in relation to a SSD it is possible to obtain an indication of the proportion of species that may be at risk.

In a recent meta-analysis of all publicly available literature we identified that cyanobacteria sensitivity to antibiotics may vary by up to 100,000 times (Le Page et al., 2017). For some antibiotics a sensitivity difference exceeding the AF of 10 
142 occurred between the most sensitive species, most commonly, Microcystis

143 aeruginosa, and the two species recommended in the OECD 201 test guideline for

144 establishing protection limits, namely Anabaena flos-aquae and Synechococcus

145 leopoliensis. Although in some cases when A. flos-aquae was the most sensitive 146 species the assessment factor of 10 did appear to be protective. The

147 aforementioned meta-analysis was based on an assessment of published data 148 and collated studies performed using different methodologies and test 149 conditions in different laboratories by different researchers. Accurate 150 numeration and confidence in relative sensitivities to antibiotic exposure in 151 cyanobacteria species are best derived through comparative experiments 152 conducted under the same test design without inter-laboratory variation.

154 To this end we optimised a microplate growth inhibition assay to assess the 155 effects of antibiotic on population growth for eight species of phylogenetically 156 diverse cyanobacteria (as assessed by their genome sequences (Shih et al., 157 2013)) culturable under laboratory conditions that are of environmental 158 relevance (Le Page et al. under review). We focused on cyanobacteria due to 159 their current key role within ERA and because they are a diverse bacterial clade 160 of photoautotrophs that are ubiquitous in both aquatic and terrestrial 161 environments, play key roles in many bacterial communities, and they have a 162 range of important ecological functions such as primary production and nitrogen 163 fixation (Falkowski, 1997).

165 Seven antibiotics were selected that spanned both a range of antibiotic classes 166 and modes of action (MoA) in order to assess the impact MoA may have on the 
degree of interspecies sensitivity observed. These included; i) three cell envelope synthesis inhibiting antibiotics, $\beta$-lactams, which target penicillin binding

169 proteins (which catalyse the building of the peptidoglycan cell membrane of 170 bacteria) namely, cefazolin and cefotaxime $\left(1^{\text {st }}\right.$ and $3^{\text {rd }}$ generation 171 cephalosporins, respectively) and ampicillin (a penicillin); ii) two DNA synthesis 172 inhibitors, sulfadiazine and sulfamethazine (sulfonamides) that prevent the 173 production of folic acid, a key precursor in the DNA synthesis pathway; and iii) 174 two protein synthesis inhibitors, erythromycin and azithromycin (macrolides), 175 which inhibit the normal functioning of the bacterial ribosome. The macrolides, 176 azithromycin and erythromycin are both candidates to be priority substances in 177 the EU Water Framework Directive watch list (Carvalho et al., 2015) and US EPA 178 contaminate list 3 (US EPA, 2009). Cefazolin and sulfamethazine have no 179 ecotoxicological data available for cyanobacteria in the open literature. 180 Sulfadiazine, cefotaxime and azithromycin have very limited ERA relevant 181 ecotoxicological data (Le Page et al., 2017).

183 We addressed the hypothesis that current protection limits for antibiotics in 184 surface water (PNECsw) are not fully protective of all cyanobacteria populations. 185 We first determined the interspecies sensitivity differences of eight species of 186 cyanobacteria by performing growth inhibition assays. We then established SSDs 187 and compared the PNEC calculated according to current guidance with the HC5 188 and $\mathrm{HC} 52.5 \%$ to determine the proportion of species that would be affected 189 following exposure to the PNEC determined from these results. Finally, based on 190 our SSDs, we calculated the proportion of cyanobacteria likely to be affected 191 using published MECs. 


\section{Materials and methods}

\subsection{Test organisms and maintenance}

194 195 196 197 198 199 200

201 Continuous cultures of exponentially growing cyanobacteria were maintained in 202 203 204 205

211 Aldrich), sulfamethazine (CAS: 57-68-1; purity $\geq 98 \%$; TCI), azithromycin 212 dihydrate (CAS: 117772-70-0; purity $\geq 98 \%$; TCI) and erythromycin (CAS: 114213 07-8; purity $\geq 98 \%$; TCI). These antibiotics span three MoAs that are detailed 214 above in the introduction. Additional rationale for their choice was based upon 
one or a combination of the following; i) being a compound of regulatory concern

216 (Carvalho et al., 2015; US EPA, 2009), ii) having suitable solubility in the test

217 media, and iii) having limited or no cyanobacteria data available in the literature.

218 A summary of the chemical properties is given in table 1.

\subsection{Growth inhibition assays}

220 Growth rate inhibition assays were performed in 96 well microplates that

221 followed a procedure adapted from the (Environment Canada, 2007) and (OECD, 222 2011) test guidelines which was developed as a medium throughput test and 223 aims to identify which species are susceptible than others and of which the 224 development and validation is documented in (Le Page et al., under review). 225 Biomass was measured using phycocyanin fluorescence as a surrogate 226 (excitation $=590 \mathrm{~nm}$, emission $=650 \mathrm{~nm}$, cut-off $=635 \mathrm{~nm}$; bottom read mode; 227 Spectromax M5 with Softmax ${ }^{\circledR}$ Pro software (Molecular Devices)). This has been 228 previously demonstrated to have a linear relationship with cell density for all 229 species except $A$. flos-aquae that had a shallower gradient at cell densities below 230 eight artificial fluorescence units (AFU, Le Page et al., under review).

232 A pre-culture for each species was prepared between three and four days prior 233 to the start of the test in $50 \mathrm{~mL}$ of $\mathrm{BG}-11$ under the experimental exposure 234 conditions (but in the absence of the antibiotic) in order to obtain exponentially 235 growing cells. A cyanobacteria inoculum was prepared in BG-11 medium at a 236 phycocyanin fluorescence of 4 AFU (twice the nominal starting inoculum). 237 Following this a geometric series of stock solutions for each test concentration 238 were prepared in BG-11 medium at double the nominal test concentrations. 
$100 \mu \mathrm{L}$ of test solution was added to $100 \mu \mathrm{L}$ of cyanobacteria inoculum to achieve

240 a final cyanobacteria density at $2 \mathrm{AFU}$ at the nominal test concentration in each

241 well. Assays were conducted in non-transparent, 96 well plates (Greiner Bio-one 242 item no. 650201), sealed with AMPLIsealTM sealer (Greiner Bio-one item no. 243676040 ) to prevent water loss due to evaporation over the test period. The plate 244 layout for the incubations described is provided in Supplementary material A.

246 The assays were run in Multitron II incubators (Infors) under the following test 247 conditions: light intensity $=4000$ lux, temperature $=28+/-1^{\circ} \mathrm{C}$ and shaking $=$ $248140 \mathrm{rpm}$. The test lengths were optimised to ensure toxicity testing was carried 249 out, as best as possible, during exponential growth for each species, and these 250 were: i) 24 hours for the fastest growing species, S. leopoliensis, S. elongates and 251 Synechococcus sp,; ii) 48 hours for A. flos-aque and Synechocystis sp. The 252 exception here was for the exposure of the Synechocystis $s p$. to sulfadiazine 253 where due to a slower growth rate than expected, an exposure period of 72 254 hours was adopted; iii) 72 hours for the slower growing species, $A$. cylindrical, $C$. 255 gracile and G. herdmanii. (Le Page et al., under review) provides further 256 discussion around the selection of exposure times and the potential 257 consequences for their extension or reduction, although we highlight that with 258 the current set up we cannot discern the magnitude of effect of the technical 259 uncertainty caused by comparing several species and how this may impact on 260 the biological differences observed.

262 Daily cell density determinations were made for each well via measurement of 263 phycocyanin fluorescence. $\mathrm{pH}$ was measured in the stocks and in a replicate of 
264 each test concentration for each species at the end of the test using micro $\mathrm{pH}$

265 meter (Jenco 6230N; pH probe: Hanna instruments HI1083) to ensure

266 fluctuations did not exceed the acceptable limits of \pm 0.2 as defined by most

267 standardised test guidelines (OECD, 2011).

268

269 For the azithromycin exposure, dimethyl sulfoxide (DMSO) was used as a solvent

270 carrier at a concentration of $10 \mu \mathrm{l} / \mathrm{L}$. Ten solvent control replicates were

271 employed and comparisons of the dilution water control and solvent control

272 replicates for all species are provided in Supplementary material A. Growth rate

273 was found not to be significantly different from the dilution water control for any

274 cyanobacteria with exception of $A$. flos-aquae and $S$. elongates where small but

275 significant decreases in growth rate $(p<0.01)$ were observed in the solvent

276 control (two tailed t.test in R, version 3.3.0; R Project for Statistical Computing,

277 Vienna, Austria). All dose-response curves and subsequent statistical

278 comparisons with antibiotic exposures were performed using the solvent control

279 data. 


\begin{tabular}{|c|c|c|c|c|c|}
\hline Antibiotic & $\begin{array}{c}\text { Primary } \\
\text { pharmacological } \\
\text { Target a }\end{array}$ & $\begin{array}{c}\text { Log } \\
\text { Kow } \mathbf{b}\end{array}$ & pKa $^{\mathbf{b}}$ & $\begin{array}{c}\mathbf{L o g} \\
\mathbf{D o w} \\
\text { (pH 8) } \mathbf{b}\end{array}$ & $\begin{array}{c}\text { Solubility } \\
\mathbf{a t} \mathbf{~ p H ~ 8 . 0 ~} \mathbf{~ b} \\
\mathbf{( g / L )}\end{array}$ \\
\hline Cefazolin & $\begin{array}{c}\text { Penicillin } \\
\text { binding protein }\end{array}$ & -1.52 & $\begin{array}{c}2.84 \text { (acid) } \\
0.26 \text { (base) }\end{array}$ & -5.04 & 454.5 \\
\hline Cefotaxime & $\begin{array}{c}\text { Penicillin } \\
\text { binding protein }\end{array}$ & -1.49 & $\begin{array}{c}2.73 \text { (acid) } \\
3.58 \text { (base) }\end{array}$ & -4.24 & 455.5 \\
\hline Ampicillin & $\begin{array}{c}\text { Penicillin } \\
\text { binding protein }\end{array}$ & -2 & $\begin{array}{c}3.24 \text { (acid) } \\
7.23 \text { (base) }\end{array}$ & -2.72 & 0.04 \\
\hline Sulfadiazine & $\begin{array}{c}\text { Dihydropteroate } \\
\text { synthetase }\end{array}$ & -0.39 & $\begin{array}{c}6.99 \text { (acid) } \\
2.01 \text { (base) }\end{array}$ & -0.33 & 8.91 \\
\hline Azithromycin & $\begin{array}{c}\text { Bacterial } \\
\text { ribosome }\end{array}$ & 2.44 & $\begin{array}{c}12.43 \text { (acid) } \\
9.57 \text { (base) }\end{array}$ & -0.08 & 1810 \\
\hline Erythromycin & $\begin{array}{c}\text { Bacterial } \\
\text { ribosome }\end{array}$ & 2.6 & $\begin{array}{c}12.45 \text { (acid) } \\
\text { (base) }\end{array}$ & 1.55 & 43.3 \\
\hline
\end{tabular}

281 Table 1 - Chemical properties of antibiotics. ${ }^{a}$ according to drugbank (www.drugbank.ca).

282 b predicted by ChemAxon (www.chemicalize.org)

\subsection{Chemical analysis}

284 The concentrations of antibiotics in the stocks and in three exposure replicates

285 for all concentrations and in each species at the end of the tests were measured 286 using liquid chromatography-mass spectrometry (method supplied in

287 Supplementary material A). Following the final cell density determination of the 288 assay, microplates were centrifuged at $4000 \mathrm{rpm}$ for 30 minutes. $150 \mu \mathrm{L}$ of 289 supernatant was carefully removed and transferred to a deep well microplate 290 (96-well, 2ml; Porvair Sciences) with acetonitrile (50\% volume). Where 291 necessary samples were further diluted to within the calibration range. All 292 chemical concentrations are reported as free acids and bases.

293 In the instances where analytical data was <LOQ or where an extraction error 294 occurred (see Supplementary material B and Table S.B1) these 

Limits of quantification (LOQ) for each antibiotic are given in Table S.B2.

298 The MECs for each antibiotic were obtained from Umweltbundesamt's (UBA)

299 'Pharmaceuticals in the environment' database (Umwelt bundesamt, 2018).

300 MECs from all matrices that were measured in, or able to be converted into $\mu \mathrm{g} / \mathrm{L}$

301 were extracted for use. Measurements of $0 \mu \mathrm{g} / \mathrm{L}$ were removed as they represent 302 either the absence of the antibiotic or presence below the limit of detection, 303 which make this analysis assume a worst-case scenario by moving the median to 304 higher concentrations. MECs from matrixes such as inflows to WWTP, sewage 305 sludge or untreated hospital and industrial effluents were also removed from the 306 analysis to leave only environmentally relevant MECs.

\subsubsection{Growth rate calculations}

309 Growth rate of cyanobacteria was calculated according to equation below based

310 on the phycocyanin fluorescence at the start and the end of the assay.

311

$$
\text { Growth Rate }=\frac{\ln \mathrm{X}_{j}-\ln \mathrm{X}_{i}}{\mathrm{t}_{j}-\mathrm{t}_{i}}
$$

313 where

$\mathrm{X}_{i}=$ cell density at time $\mathrm{t}_{i}$ $\mathrm{t}_{i}=i^{\prime}$ th time point 
317 Dose-response curves were fitted in R (version 3.3.0; R Project for Statistical

318 Computing, Vienna, Austria) using the drc package (Ritz et al., 2015). For all 319 pairs of bacterial species and antibiotics, growth rate data were fitted to log320 logistic (3, 4 and 5 parameters) and Weibull distributions ( 4 and 5 parameters).

321 Of these, the optimal distribution was selected based of the log-likelihood score 322 to represent the data. From this fitted distribution estimates of the 10 and 50\% 323 effective concentrations $\left(\mathrm{EC}_{\mathrm{x}}\right)$ and associated confidence limits were determined. 324 Data handing for the growth rate determinants for each species are provided in 325 Supplementary material A.

\subsubsection{Species Sensitivity Distributions}

327

328

330

The HC5 and associated confidence intervals were determined from

SSDs were constructed in R (version 3.3.0; R Project for Statistical Computing, Vienna, Austria) using the fitdistrplus package (Delignette-Muller and Dutang, 2015) following procedure outlined in the MOSAIC SSD platform (Kon Kam King et al., 2014). The $95 \%$ confidence intervals of the $\mathrm{EC}_{10}$ for each species were used as interval-censored data (i.e. not a single fixed value but a range between the 95\% confidence limits). This allowed for the incorporation of the uncertainty around the $\mathrm{EC}_{10}$ into the SSD and this increases confidence in the SSD output (Kon Kam King et al., 2014). Six parametric distributions were fitted to the data: i) normal, ii) log-normal, iii) Weibull, iv) log-logistic, v) gamma and vi) exponential. The best fitting distribution was selected based upon a combination of the Akaike Information Criterion (AIC) score.

bootstrapping of the data (5000 iterations) based on the parameters of the fitted 
340 distribution. A similar protocol was followed to derive the SSD, HC5 and

341 confidence intervals from the NOEC data but for this the NOEC values were used 342 as non-censored data.

\section{3. Results}

\subsection{Antibiotic exposure concentrations}

345 The measured concentrations of the antibiotics in each microplate assay, 346 calculated using a geometric mean of the concentrations at the start (stocks) and 347 end (exposure replicates) of the test, are provided in the Supplementary material 348 B (figures S.B1 - S.B14). Overall concentrations of the antibiotics in the test 349 media varied with losses due, in part, to the presence of the bacteria. These 350 losses differed across the various antibiotics tested and species (graphs S.B15 351 S.B21; determined as the difference between concentrations in the wells 352 containing cyanobacteria and blank replicates (without cyanobacteria)).

354 For cefazolin, mean measured concentrations in the exposure replicates ranged 355 between 14 to $32 \%$ of the nominal concentrations (Fig S.B1). The greatest losses 356 of cefazolin occurred in the exposures to S. elongates and Synechococcus sp.

358 Mean measured concentrations of cefotaxime in the exposure replicates ranged 359 between 18 and $44 \%$ of nominal (Fig S.B3). The greatest reductions in the 360 exposure replicates compared with replicates without cyanobacteria were for 361 the Synechococcus genus (Fig S.B16). 
363 Mean measured concentrations of ampicillin in the exposure replicates ranged

364 between 44 and $95 \%$ of nominal (Fig S.B5). In the presence of the cyanobacteria 365 there were generally between 10 and 30\% additional reductions compared with 366 the replicates without bacteria, but was most pronounced in the A. cylindrical 367 exposure replicates (S.B17).

369 Mean measured concentrations of sulfadiazine in the exposure replicates were 370 between 101 and 142\% of nominal (Fig S.B7). The high measured concentrations 371 of up to $142 \%$ of nominal occurred in the nominal $2.36,145$ and $1140 \mu \mathrm{g} / \mathrm{L}$ test 372 concentrations and they would increase the uncertainty around toxicity 373 estimates calculated. However, due to the lack of sensitivity of the cyanobacteria 374 to sulfadiazine (see below) this doesn't affect any conclusions drawn. Reductions 375 in sulfadiazine concentrations due to the presence of the cyanobacteria varied 376 across tests concentrations (S.B18).

Mean measured concentrations of sulfamethazine in the exposure replicates 379 ranged between 87 to and 134\% of nominal (Fig S.B9). Extraction errors for 380 nominal concentrations 907 and $1633 \mu \mathrm{g} / \mathrm{L}$ in the S. elongates exposure meant 381 that these had to be excluded for the analyses.

383 Mean measured concentrations of erythromycin in the exposure replicates were 384 between 71 and $100 \%$ of nominal (Fig S.B11) with exception of the nominal $3853.77 \mu \mathrm{g} / \mathrm{L}$ test concentration (53\% of nominal). Erythromycin concentrations 386 were lowered by up to $50 \%$ over the exposure period and the presence of the 387 cyanobacteria in the exposure replicates caused additional erythromycin losses 
of on average of 10 and $20 \%$ (but up to 60\%) compared to replicates without cyanobacteria present (Fig S.B20).

Mean measured concentrations of azithromycin in the exposure replicates ranged between 23 and 79\% of nominal (Fig S.B13). Azithromycin 393 concentrations in the exposure and blank replicates at the end of the exposures 394 were considerably lower, by up to $96 \%$. The presence of all species of 395 cyanobacteria had an effect of reducing the test concentrations further by 396 between 10 and 15\% (Fig S.B21).

\subsection{Growth inhibition, species sensitivity distributions and protection} limit analysis:

399 The dose-response curves for growth inhibition of the eight cyanobacteria for 400 each antibiotic tested are presented in Figure 1. The EC10s, EC50s and NOECs for 401 the experimental data are given in Table 2 (raw data are provided, and shown 402 graphically in Supplementary material C, figures S.C1 - S.C7). All dose-response 403 analyses are based upon geometric mean measured test concentrations. The pHs 404 at the start and at the end of the tests are provided in Supplementary material D. 405

406 The data in Figure 2 presents the SSDs, based upon cyanobacteria $\mathrm{EC}_{10 \mathrm{~s}}$ for each 407 antibiotic, together with PNECs based upon the NOEC of the most sensitive 408 species tested (PNEClowest) and the PNECs, based upon the two Organisation for

409 Economic Co-operation and Development (OECD) test guideline recommended 410 species (from which all PNECs derived for regulatory purposes are likely derived

411 from) A. flos-aquae (PNEC flos-aquae $_{\text {- }}$ and S. leopoldensis (PNECs.leopoldensis). SSDs 
based upon cyanobacteria NOECs are provided in Supplementary material C

413 (figure S.C8). It was not possible to establish the SSDs for sulfamethazine or for 414 sulfadiazine as neither produced a full dose response curve from which to 415 calculate an $\mathrm{EC}_{10}$.

416 The data in Table 2 provide values for the HC5, PNECs and the proportion of 417 cyanobacteria affected at these concentrations, predicted from the SSD (based on 418 the $\mathrm{EC}_{10 \mathrm{~s}}$ ). Table 3 gives the highest and median MECs and the proportion of 419 cyanobacteria affected at these concentrations predicted from the SSD (based on 420 the $\mathrm{EC}_{10 \mathrm{~S}}$ ). The same information as Tables 2 and 3 are provided in Tables S.C1 421 and S.C2 but here using the SSD based upon NOEC data. Table SC.3 provides the 422 best fitting distributions used for establishing the SSD.

$423 \mathrm{EC}_{10 \mathrm{~S}}$ for the different cyanobacteria exposure for cefazolin ranged between 2.4 424 and $124 \mu \mathrm{g} / \mathrm{L}$ and the EC 50 s ranged between 4.1 to $283 \mu \mathrm{g} / \mathrm{L}$ (Figure 1 and Table 425 1). Based upon both $\mathrm{EC}_{10}$ and $\mathrm{EC}_{50}$ A. flos-aquae and $G$. herdmanii were the most 426 sensitive species to cefazolin. Species in the Synechococcus genera (S. leopoliensis, 427 S. elongates and Synechococcus sp.) along with Synechocystis sp. were the least 428 sensitive. Synechococcus sp. was up to 70 times less sensitive than the most 429 sensitive species based on the EC 50 . The HC5 for cefazolin, based on EC 10 s, was $4301.13 \mu \mathrm{g} / \mathrm{L}$, which was 7.5 times higher than the lowest PNEC (for A. flos-aquae) 431 but 4 times lower than that based on S. leopoldensis (Figure 2 and Table 2). The 432 predicted proportion of cyanobacteria affected at the PNECs ranged between $433 \quad 0.95$ and $13.3 \%$ depending on which species was used to derive the PNEC (Table 434 2). The HC5 based on the NOEC data was $5 \mu \mathrm{g} / \mathrm{L}, 4$ times higher than when based 435 on the $\mathrm{EC}_{10}$ (Table SC.1). The median MEC was predicted to affect a small fraction 
436 of cyanobacteria $(<1 \%)$ based on the SSD. The highest recorded MEC $(42.9 \mu \mathrm{g} / \mathrm{L}$;

437 the maximum concentration observed in a range of effluents in Taiwan, including 438 manufacturing and hospital effluents (Lin et al., 2008)) was predicted to affect $43960.2 \%$ of cyanobacteria (Table 3) with the second highest MEC of $6.2 \mu \mathrm{g} / \mathrm{L}$ 440 affecting $16.2 \%$ of cyanobacteria. The median MEC of 6 hospital effluents in the 441 same study, of $6.2 \mu \mathrm{g} / \mathrm{L}$ (Lin et al., 2008), would affect $17.3 \%$ of cyanobacteria 442 based on the SSD.

$444 \quad \mathrm{EC}_{10 \mathrm{~s}}$ for the different cyanobacteria exposure to cefotaxime ranged between 1.2 445 and $39.8 \mu \mathrm{g} / \mathrm{L}$ and EC50s ranged between 2.2 and $98 \mu \mathrm{g} / \mathrm{L}$ (Figure 1 and Table 1 ). 446 The maximum difference in sensitivity (45 times) occurred between $A$. flos-aquae 447 (the most sensitive) and Synechococcus sp (the least sensitive). The four least 448 sensitive species, S. leopoliensis, Synechocystis sp., $S . \quad$ elongates and 449 Synechococcus sp., were also the least sensitive species to cefazolin, the other 450 cephalosporin tested, with the same order of relative sensitivity. The HC5 for 451 cefotaxime, based upon $\mathrm{EC}_{10 \mathrm{~s}}$, was $0.67 \mu \mathrm{g} / \mathrm{L}$, which was 4 times higher than the 452 lowest PNEC (for $A$. cylindrica) and approximately the same value as for the 453 PNEC based upon S. leopoldensis (Figure 2 and Table 2). The predicted 454 proportion of cyanobacteria affected at the PNECs ranged between 1.3 and 5.2\% 455 depending on which species was used to derive the PNEC (Table 2). The HC5 456 based upon the NOEC data was approximately the same as when based on the $457 \quad \mathrm{EC}_{10}$ (Table SC.1). The median MEC had little effect upon cyanobacteria based on 458 the SSD. The highest recorded MEC $(41.9 \mu \mathrm{g} / \mathrm{L}$; the maximum concentration 459 observed in a range of effluents in Taiwan, including manufacturing and hospital 460 effluents (Lin et al., 2008)) was predicted to affect $95.9 \%$ of cyanobacteria (Table 
461 3). The median MEC of 6 hospital effluents in the same study, of $0.413 \mu \mathrm{g} / \mathrm{L}$ (Lin

462 et al., 2008), would affect 3.1\% of cyanobacteria based on the SSD.

463

$464 \mathrm{EC}_{10 \mathrm{~S}}$ for the different cyanobacteria exposure to ampicillin ranged between 5.9 465 and $44.6 \mu \mathrm{g} / \mathrm{L}$ and $\mathrm{EC}_{50}$ s ranged between 8.4 and $81.4 \mu \mathrm{g} / \mathrm{L}$ (Figure 1 and Table

466 1). Based on the $\mathrm{EC}_{50}$, there was a difference in sensitivity of approximately 10 467 times (9.7) between the most sensitive (C. gracile) and least sensitive species 468 (A. cylindrical). C. gracile was 3 times more sensitive than the next most sensitive 469 species, S. leopoliensis. The remaining cyanobacteria all had similar sensitivities 470 with EC50s of between 52 and $81.4 \mu \mathrm{g} / \mathrm{L}$. The HC5 for ampicillin, based on $\mathrm{EC}_{10 \mathrm{~s}}$, 471 was $8.6 \mu \mathrm{g} / \mathrm{L}$, which was 17.5 times higher than the lowest PNEC (for C. gracile) 472 and 2.9 and 7.4 times higher than the PNECs based on A. flos-aquae and 473 S. leopoldensis, respectively (Figure 2 and Table 2). The predicted proportion of 474 cyanobacteria affected at the PNECs ranged between 0.9 and $1.6 \%$ depending on 475 which species was used to derive the PNEC (Table 2). The HC5 based upon the 476 NOEC data was approximately the same as those based on the $\mathrm{EC}_{10}$ (Table SC.1). 477 The median MEC indicated little effect upon cyanobacteria based on the SSD. The 478 highest recorded MEC of 27.1 $\mu \mathrm{g} / \mathrm{L}$ (WWTP effluent in India (Mutiyar and Mittal, 479 2013)) was predicted to affect $44.3 \%$ of the cyanobacteria (Table 3 ).

481 Exposure to sulfadiazine only caused partial inhibition of growth of the 482 cyanobacteria tested (Figure 1). It was possible to fit log-logistic or Weibull 483 distributions to the growth data but as growth inhibition ceased before the point 484 of $50 \%$ growth inhibition $\mathrm{EC}_{10}$ or $\mathrm{EC}_{50}$ values (and therefore SSDs) could not be 
calculated. The highest recorded MEC was $30.5 \mu \mathrm{g} / \mathrm{L}$; treated WWTP effluent in east China (Chen et al., 2012), whilst the median MEC was $0.019 \mu \mathrm{g} / \mathrm{L}$.

As for sulfadiazine, sulfamethazine did not induce full growth inhibition for any of the cyanobacteria tested (Figure 1) preventing the ability to calculate $\mathrm{EC}_{10}$ or $\mathrm{EC}_{50}$ values (or SSDs). C. gracile was the most sensitive species to the growth 491 inhibition effects of sulfamethazine (a 50\% reduction in growth rate was 492 observed at an exposure concentration of $1465 \mu \mathrm{g} / \mathrm{L}$ ). At the highest tested 493 exposure concentration $(10,000 \mu \mathrm{g} / \mathrm{L})$ there was between a $30 \%$ and $40 \%$

494 decrease in growth rate in A. flos-aquae, A. cylindrical, S. leopoliensis, S. elongates, 495 Synechococcus sp., and G. herdmanii. Synechocystis sp was far less affected with 496 only a $4 \%$ inhibition of growth at the highest tested concentration. The highest recorded MEC was 25.4 $\mu \mathrm{g} / \mathrm{L}$; treated WWTP effluent in Korea (Sim et al., 2011), whilst the median MEC was $0.015 \mu \mathrm{g} / \mathrm{L}$.

500 EC10s for the different cyanobacteria exposure to erythromycin ranged between 50121.1 and $58.8 \mu \mathrm{g} / \mathrm{L}$ and the EC50s were between 43.4 and $135.1 \mu \mathrm{g} / \mathrm{L}$ (Figure 1 502 and Table 1). Based upon the $\mathrm{EC}_{50}$, there was only a small interspecies difference 503 in sensitivity; 3.1 times, between the most sensitive (A. cylindrical) and least 504 sensitive species (A. flos-aquae). The HC5 for erythromycin, based upon $\mathrm{EC}_{10 \mathrm{~s}}$, 505 was $21.3 \mu \mathrm{g} / \mathrm{L}$, which was 34.4 times higher than the lowest PNEC (for 506 S. elongatus) and 7.3 and 6.9 times higher than the PNECs for A. flos-aquae and 507 S. leopoldensis, respectively (Figure 2 and Table 2). The proportion of 508 cyanobacteria affected at the PNECs was $<1 \%$ for all PNECs irrespective of which 509 species was used to derive it (Table 2). The HC5 based upon the NOEC data was 
5103.5 times lower than when based on the $\mathrm{EC}_{10}$ (Table SC.2). No species of

511 cyanobacteria are predicted to be affected by the MECs based on the SSD

512 (highest MEC was $7.8 \mu \mathrm{g} / \mathrm{L}$; untreated manufacturing discharge in China (Lin and

513 Tsai, 2009)) (Table 3). The HC5 in this study was 107 times higher (HC52.5 was

51481 times higher) than the PNEC in the European Unions watch list of priority

515 substances for erythromycin is $0.2 \mu \mathrm{g} / \mathrm{L}$ (Loos et al., 2018), but a PNEC based

516 upon the lowest NOEC, based on S. elongates, would have been only $<3$ times

517 higher $($ NOEC $<0.62 \mu \mathrm{g} / \mathrm{L})$.

518

$519 \mathrm{EC}_{10 \mathrm{~S}}$ for the different cyanobacteria exposure to azithromycin ranged between

5203.2 and $17.7 \mu \mathrm{g} / \mathrm{L}$ and $\mathrm{EC}_{50}$ s ranged between 5.4 and $33.8 \mu \mathrm{g} / \mathrm{L}$ (Figure 1 and

521 Table 1). Based upon the $\mathrm{EC}_{50}$, there was difference in sensitivity of 6.3 times

522 only between the most sensitive (A. cylindrical) and least sensitive species

523 (Synechococcus sp.). The HC5 for azithromycin, based on $\mathrm{EC}_{10 \mathrm{~s}}$, was $3.2 \mu \mathrm{g} / \mathrm{L}$,

524 which was 21 times higher than the lowest PNEC (for G. herdmanii) and 3.1 and

52516.6 times higher than the PNECs for A. flos-aquae and S. leopoldensis,

526 respectively (Figure 2 and Table 2). The predicted proportion of cyanobacteria

527 affected at the PNECs was $<1 \%$ for all PNECs irrespective of which species was

528 used to derive it (Table 2). The HC5 based upon the NOEC data was

529 approximately half as much as when based on the $\mathrm{EC}_{10}$ (Table SC.2). The median

530 MEC had no effect upon cyanobacteria based on the SSD, whilst the highest

531 recorded MEC of $2.8 \mu \mathrm{g} / \mathrm{L}$ (from a WWTP in Las Vegas; (Jones-Lepp et al., 2012))

532 was predicted to affect 3\% of cyanobacteria (Table 3). The HC5 in this study was

533166 times higher (HC52.5 was 111 times higher) than the PNEC in the European

534 Unions watch list of priority substances for azithromycin, $0.019 \mu \mathrm{g} / \mathrm{L}$ (Loos et al., 
535 2018), but a PNEC based upon the lowest NOEC, based on G. herdmenii, would 536 have been only $<8$ times higher $($ NOEC $=0.15 \mu \mathrm{g} / \mathrm{L})$. 


\section{Cell membrane inhibitors}
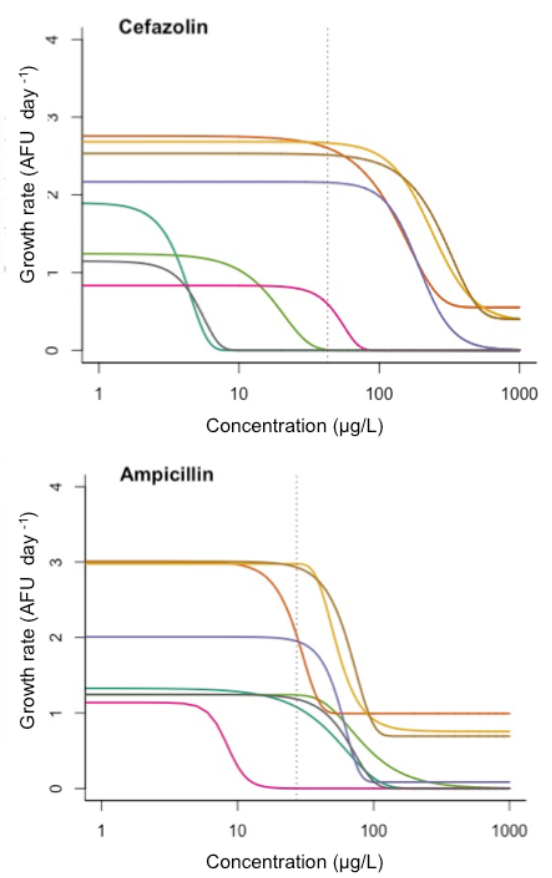

DNA synthesis inhibitors

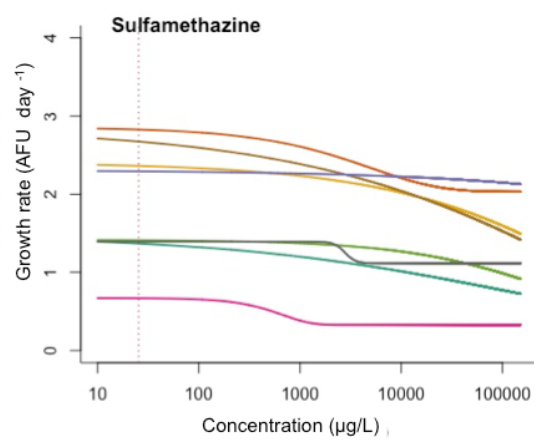

Protein synthesis inhibitors

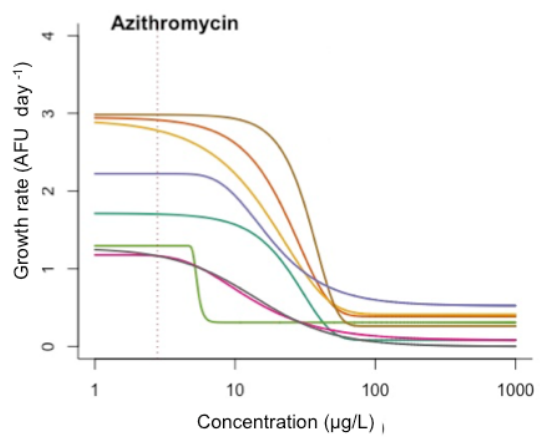

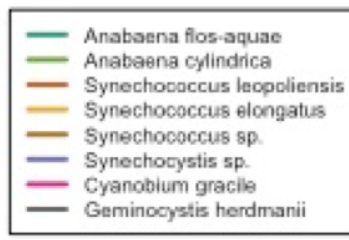
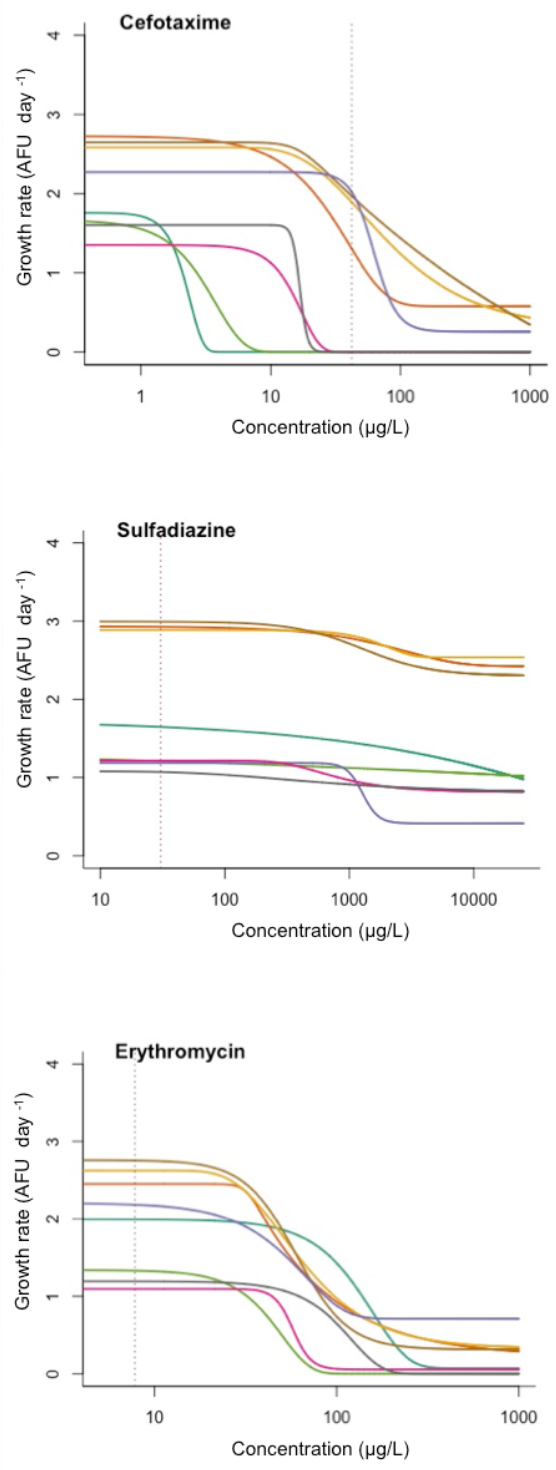

538 Figure 1 - Fitted concentration - response curves showing the effects of antibiotics on the growth rate of cyanobacteria. Curves are based upon 10 exposure concentrations Antibiotics are arranged (vertical panels) according to their mode of action. Red dotted line indicates the highest measured environmental concentration (MEC) in UBA database (Umwelt bundesamt, 2018). Raw

542 data plots are presented in Supplementary material C. In some cases the number of

543 concentrations tested falling on the slope of the dose response curve may be low $(<3)$ and this 544 may influence the confidence (robustness) of the toxicity estimation. 


\begin{tabular}{|c|c|c|c|c|c|c|c|c|c|}
\hline Antibiotic & Species & $\begin{array}{c}\mathrm{EC}_{10} \\
\text { estimate } \\
(\mu \mathrm{g} / \mathrm{L})\end{array}$ & $\begin{array}{c}\mathrm{EC}_{10} \\
\text { Low CL } \\
(\mu \mathrm{g} / \mathrm{L})\end{array}$ & $\begin{array}{c}\mathrm{EC}_{10} \\
\text { High CL } \\
(\mu \mathrm{g} / \mathrm{L})\end{array}$ & $\begin{array}{c}E_{50} \\
\text { estimate } \\
(\mu \mathrm{g} / \mathrm{L})\end{array}$ & $\begin{array}{c}E_{50} \\
\text { Low CL } \\
(\mu g / L)\end{array}$ & $\begin{array}{c}\mathrm{EC}_{50} \\
\text { High CL } \\
(\mu \mathrm{g} / \mathrm{L})\end{array}$ & $\begin{array}{l}\text { NOEC } \\
(\mu \mathrm{g} / \mathrm{L})\end{array}$ & $\begin{array}{l}\text { Difference in } \\
\text { sensitivity a }\end{array}$ \\
\hline \multirow{8}{*}{ Cefazolin } & A. flos-aquae & 2.4 & 1.7 & 3.0 & 4.1 & 3.7 & 4.5 & 1.5 & \multirow{8}{*}{70} \\
\hline & A. cylindrical & 7.9 & 2.9 & 12.8 & 17.8 & 15.4 & 20.2 & 6.4 & \\
\hline & C. gracile & 32.2 & 24.8 & 39.5 & 51.3 & 47.5 & 55.1 & 44.0 & \\
\hline & G. herdmanii & 3.1 & 2.6 & 3.5 & 5.1 & 4.8 & 5.3 & 4.5 & \\
\hline & S. elongates & 111.3 & 97.3 & 125.3 & 238.0 & 217.6 & 258.3 & 66.4 & \\
\hline & S. leopoliensis & 51.6 & 41.4 & 61.9 & 134.1 & 122.5 & 145.6 & 45.3 & \\
\hline & Synechococcus sp & 124.1 & 101.5 & 146.8 & 283.2 & 263.6 & 302.8 & 93.4 & \\
\hline & Synechocystis sp & 104.5 & 80.9 & 128.1 & 191.3 & 170.0 & 212.5 & 157.0 & \\
\hline \multirow{8}{*}{ Cefotaxime } & A. flos-aquae & 1.4 & 1.0 & 1.8 & 2.2 & 2.0 & 2.4 & 1.9 & \multirow{8}{*}{45} \\
\hline & A. cylindrical & 1.2 & 0.3 & 2.2 & 3.1 & 2.2 & 4.1 & 1.7 & \\
\hline & C. gracile & 8.3 & 7.5 & 9.2 & 15.4 & 14.8 & 16.0 & 9.6 & \\
\hline & G. herdmanii & 15.1 & 8.9 & 21.4 & 17.7 & 14.7 & 20.6 & 9.9 & \\
\hline & S. elongates & 20.8 & 16.2 & 25.4 & 75.4 & 56.3 & 94.4 & 12.7 & \\
\hline & S. leopoliensis & 8.7 & 7.0 & 10.3 & 31.0 & 28.7 & 33.3 & 7.0 & \\
\hline & Synechococcus sp & 16.2 & 11.5 & 20.8 & 97.9 & 74.2 & 121.6 & 12.1 & \\
\hline & Synechocystis sp & 39.8 & 28.3 & 51.3 & 62.3 & 53.7 & 71.0 & 46.3 & \\
\hline \multirow{5}{*}{ Ampicillin } & A. flos-aquae & 18.7 & 11.6 & 25.9 & 52.4 & 45.2 & 59.7 & 30.2 & \multirow{5}{*}{9.7} \\
\hline & A. cylindrical & 44.6 & 40.0 & 49.3 & 81.4 & 73.5 & 89.2 & 37.1 & \\
\hline & C. gracile & 5.9 & 5.1 & 6.7 & 8.4 & 7.4 & 9.4 & 4.9 & \\
\hline & G. herdmanii & 34.3 & 27.2 & 41.4 & 64.4 & 60.5 & 68.3 & 12.2 & \\
\hline & S. elongates & 38.8 & 35.0 & 42.7 & 54.0 & 50.4 & 57.6 & 36.4 & \\
\hline
\end{tabular}




\begin{tabular}{|c|c|c|c|c|c|c|c|c|c|}
\hline Antibiotic & Species & $\begin{array}{c}\mathrm{EC}_{10} \\
\text { estimate } \\
(\mu \mathrm{g} / \mathrm{L})\end{array}$ & $\begin{array}{c}\mathrm{EC}_{10} \\
\text { Low CL } \\
(\mu \mathrm{g} / \mathrm{L})\end{array}$ & $\begin{array}{c}\mathrm{EC}_{10} \\
\text { High CL } \\
(\mu \mathrm{g} / \mathrm{L})\end{array}$ & $\begin{array}{c}\mathrm{EC}_{50} \\
\text { estimate } \\
(\mu \mathrm{g} / \mathrm{L})\end{array}$ & $\begin{array}{c}\mathrm{EC}_{50} \\
\text { Low CL } \\
(\mu \mathrm{g} / \mathrm{L})\end{array}$ & $\begin{array}{c}\mathrm{EC}_{50} \\
\mathrm{High} \mathrm{CL} \\
(\mu \mathrm{g} / \mathrm{L})\end{array}$ & $\begin{array}{l}\text { NOEC } \\
(\mu \mathrm{g} / \mathrm{L})\end{array}$ & $\begin{array}{l}\text { Difference in } \\
\text { sensitivity a }\end{array}$ \\
\hline & S. leopoliensis & 16.2 & 11.8 & 20.6 & 27.5 & 25.1 & 29.9 & 11.5 & \\
\hline & Synechococcus $s p$ & 38.0 & 30.1 & 45.9 & 66.6 & 63.0 & 70.1 & 31.5 & \\
\hline & Synechocystis sp & 36.5 & 25.8 & 47.2 & 57.1 & 50.7 & 63.5 & 34.2 & \\
\hline \multirow{8}{*}{ Sufadiazine } & A. flos-aquae & $\mathrm{N} / \mathrm{A}$ & $\mathrm{N} / \mathrm{A}$ & $\mathrm{N} / \mathrm{A}$ & $\mathrm{N} / \mathrm{A}$ & N/A & $\mathrm{N} / \mathrm{A}$ & $\mathrm{N} / \mathrm{A}$ & \multirow{8}{*}{ N/A } \\
\hline & A. cylindrical & $\mathrm{N} / \mathrm{A}$ & $\mathrm{N} / \mathrm{A}$ & $\mathrm{N} / \mathrm{A}$ & $\mathrm{N} / \mathrm{A}$ & $\mathrm{N} / \mathrm{A}$ & $\mathrm{N} / \mathrm{A}$ & $\mathrm{N} / \mathrm{A}$ & \\
\hline & C. gracile & $\mathrm{N} / \mathrm{A}$ & $\mathrm{N} / \mathrm{A}$ & $\mathrm{N} / \mathrm{A}$ & N/A & N/A & N/A & N/A & \\
\hline & G. herdmanii & $\mathrm{N} / \mathrm{A}$ & $\mathrm{N} / \mathrm{A}$ & $\mathrm{N} / \mathrm{A}$ & $\mathrm{N} / \mathrm{A}$ & $\mathrm{N} / \mathrm{A}$ & $\mathrm{N} / \mathrm{A}$ & N/A & \\
\hline & S. elongates & N/A & $\mathrm{N} / \mathrm{A}$ & $\mathrm{N} / \mathrm{A}$ & $\mathrm{N} / \mathrm{A}$ & $\mathrm{N} / \mathrm{A}$ & N/A & N/A & \\
\hline & S. leopoliensis & N/A & $\mathrm{N} / \mathrm{A}$ & $\mathrm{N} / \mathrm{A}$ & N/A & $\mathrm{N} / \mathrm{A}$ & N/A & N/A & \\
\hline & Synechococcus $s p$ & N/A & $\mathrm{N} / \mathrm{A}$ & N/A & $\mathrm{N} / \mathrm{A}$ & $\mathrm{N} / \mathrm{A}$ & $\mathrm{N} / \mathrm{A}$ & $\mathrm{N} / \mathrm{A}$ & \\
\hline & Synechocystis sp & N/A & $\mathrm{N} / \mathrm{A}$ & N/A & 1275 & 1058 & 1493 & 380 & \\
\hline \multirow{8}{*}{ Sulfamethazine } & A. flos-aquae & N/A & $\mathrm{N} / \mathrm{A}$ & N/A & $\mathrm{N} / \mathrm{A}$ & N/A & $\mathrm{N} / \mathrm{A}$ & N/A & \multirow{8}{*}{$\mathrm{N} / \mathrm{A}$} \\
\hline & A. cylindrical & $\mathrm{N} / \mathrm{A}$ & $\mathrm{N} / \mathrm{A}$ & $\mathrm{N} / \mathrm{A}$ & $\mathrm{N} / \mathrm{A}$ & $\mathrm{N} / \mathrm{A}$ & $\mathrm{N} / \mathrm{A}$ & $\mathrm{N} / \mathrm{A}$ & \\
\hline & C. gracile & $\mathrm{N} / \mathrm{A}$ & $\mathrm{N} / \mathrm{A}$ & N/A & $\mathrm{N} / \mathrm{A}$ & N/A & $\mathrm{N} / \mathrm{A}$ & N/A & \\
\hline & G. herdmanii & N/A & $\mathrm{N} / \mathrm{A}$ & N/A & N/A & N/A & N/A & N/A & \\
\hline & S. elongates & $\mathrm{N} / \mathrm{A}$ & $\mathrm{N} / \mathrm{A}$ & $\mathrm{N} / \mathrm{A}$ & $\mathrm{N} / \mathrm{A}$ & N/A & $\mathrm{N} / \mathrm{A}$ & N/A & \\
\hline & S. leopoliensis & N/A & N/A & N/A & $\mathrm{N} / \mathrm{A}$ & N/A & $\mathrm{N} / \mathrm{A}$ & $\mathrm{N} / \mathrm{A}$ & \\
\hline & Synechococcus $s p$ & $\mathrm{~N} / \mathrm{A}$ & $\mathrm{N} / \mathrm{A}$ & N/A & $\mathrm{N} / \mathrm{A}$ & N/A & $\mathrm{N} / \mathrm{A}$ & N/A & \\
\hline & Synechocystis sp & N/A & $\mathrm{N} / \mathrm{A}$ & N/A & $\mathrm{N} / \mathrm{A}$ & N/A & N/A & N/A & \\
\hline \multirow{3}{*}{ Azithromycin } & A. flos-aquae & 10.5 & 7.1 & 14.0 & 25.8 & 22.4 & 29.3 & 10.2 & \multirow{3}{*}{6.3} \\
\hline & A. cylindrical & 5.0 & 3.8 & 6.2 & 5.4 & 0.6 & 10.1 & 4.9 & \\
\hline & C. gracile & 4.8 & 3.8 & 5.7 & 12.5 & 10.3 & 14.6 & 9.5 & \\
\hline
\end{tabular}




\begin{tabular}{|c|c|c|c|c|c|c|c|c|c|}
\hline Antibiotic & Species & $\begin{array}{c}\mathrm{EC}_{10} \\
\text { estimate } \\
(\mu \mathrm{g} / \mathrm{L})\end{array}$ & $\begin{array}{c}\mathrm{EC}_{10} \\
\text { Low CL } \\
(\mu \mathrm{g} / \mathrm{L})\end{array}$ & $\begin{array}{c}\mathrm{EC}_{10} \\
\text { High CL } \\
(\mu \mathrm{g} / \mathrm{L})\end{array}$ & $\begin{array}{c}\mathrm{EC}_{50} \\
\text { estimate } \\
(\mu \mathrm{g} / \mathrm{L})\end{array}$ & $\begin{array}{c}\mathrm{EC}_{50} \\
\text { Low CL } \\
(\mu \mathrm{g} / \mathrm{L})\end{array}$ & $\begin{array}{c}\mathrm{EC}_{50} \\
\text { High CL } \\
(\mu \mathrm{g} / \mathrm{L})\end{array}$ & $\begin{array}{l}\text { NOEC } \\
(\mu \mathrm{g} / \mathrm{L})\end{array}$ & $\begin{array}{l}\text { Difference in } \\
\text { sensitivity a }\end{array}$ \\
\hline & G. herdmanii & 3.2 & 2.2 & 4.3 & 13.8 & 11.8 & 15.8 & 1.5 & \\
\hline & S. elongates & 4.4 & 2.7 & 6.0 & 17.4 & 14.9 & 19.9 & 3.3 & \\
\hline & S. leopoliensis & 8.7 & 6.7 & 10.6 & 23.5 & 21.6 & 25.4 & 1.9 & \\
\hline & Synechococcus sp & 17.7 & 13.5 & 21.9 & 33.8 & 31.5 & 36.1 & 2.6 & \\
\hline & Synechocystis sp & 8.6 & 5.7 & 11.4 & 18.1 & 12.9 & 23.4 & 9.6 & \\
\hline \multirow{8}{*}{ Erythromycin } & A. flos-aquae & 58.8 & 41.5 & 76.1 & 135.1 & 121.9 & 148.3 & 28.8 & \multirow{8}{*}{3.1} \\
\hline & A. cylindrical & 22.3 & 16.5 & 28.2 & 43.9 & 40.2 & 47.6 & 12.2 & \\
\hline & C. gracile & 44.5 & 15.5 & 73.5 & 57.3 & 56.0 & 58.6 & 31.2 & \\
\hline & G. herdmanii & 50.7 & 42.6 & 58.7 & 104.8 & 98.1 & 111.5 & 11.5 & \\
\hline & S. elongates & 30.1 & 26.4 & 33.9 & 63.3 & 57.7 & 68.9 & $<6.2$ & \\
\hline & S. leopoliensis & 35.0 & 28.6 & 41.3 & 63.9 & 53.6 & 74.1 & 31 & \\
\hline & Synechococcus sp & 29.1 & 23.8 & 34.4 & 59.8 & 55.6 & 64.0 & 13.4 & \\
\hline & Synechocystis sp & 21.2 & 12.3 & 30.1 & 55.7 & 49.5 & 61.8 & $<7.2$ & \\
\hline
\end{tabular}

546 Table 2 - Antibiotic 10\% and 50\% effective concentrations (ECx) and no observed effect concentrations (NOEC) for growth inhibition of eight cyanobacteria

547 species. All concentrations are reported in $\mu \mathrm{g} / \mathrm{L}$. CL = Confidence Limit. a Times difference calculated by largest ECx/smallest ECx - reported value is based on

548 largest range of $\mathrm{EC}_{10}$ and $\mathrm{EC}_{50}$. Mode of Actions: cefazolin , cefotaxime amd ampicillin are cell membrane synthesis inhibitors; sufadiazine and sulfamethazine are

549 DNA synthesis inhibitors (Anti-folates); Azithromycin and Erythromycin are Protein synthesis inhibitors. 

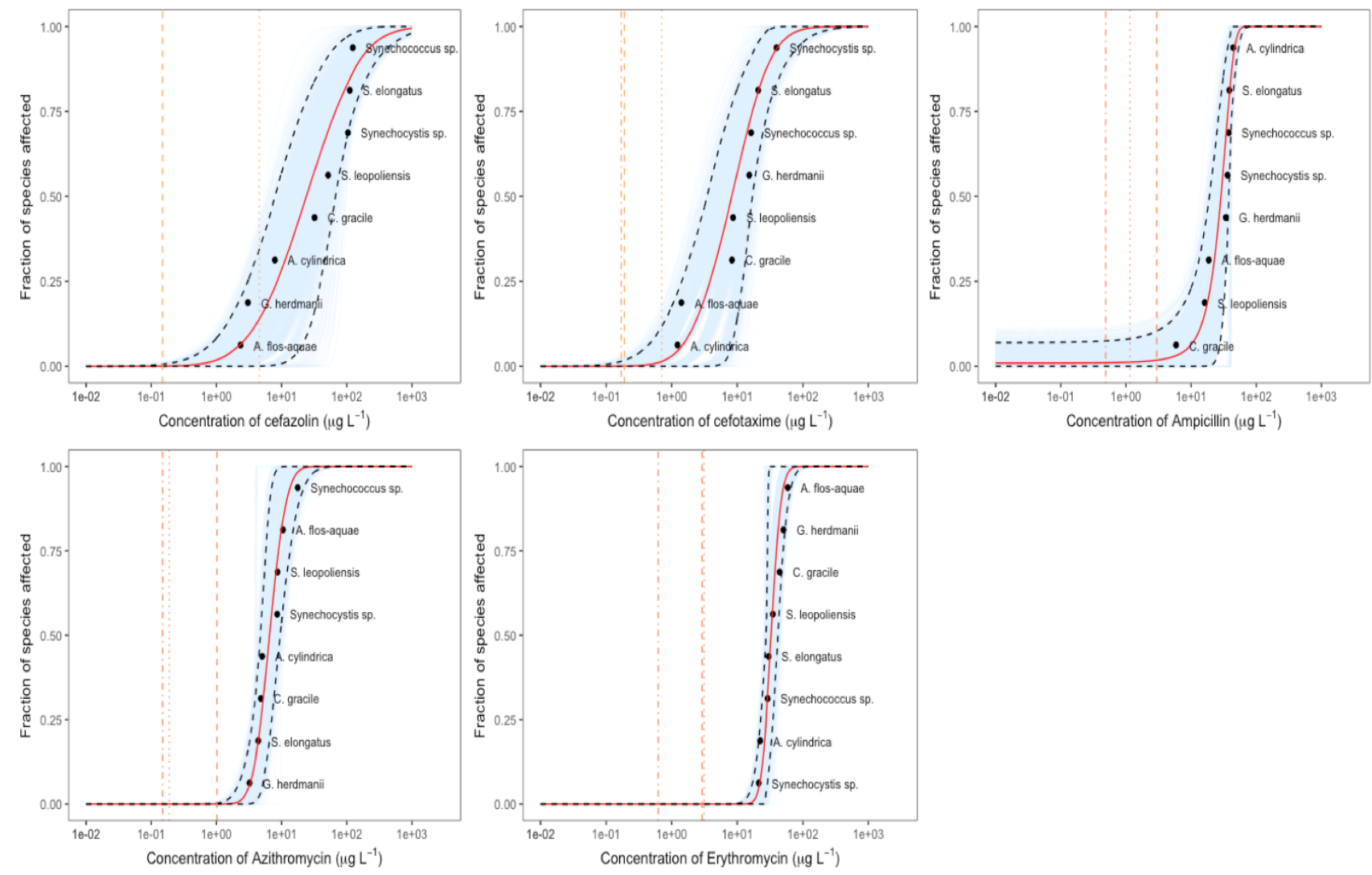

Figure 2. Species sensitivity distributions of cyanobacteria exposed to five antibiotics; cefazolin and cefotaxime (cephalosporins), ampicillin (penicillin),

552 azithromycin and erythromycin (macrolides). Red line indicates the modelled species sensitivity distribution. Dashed black lines represent upper and lower 95\%

(PNEC): Dot-dash orange line= PNEClowest; Dashed orange line $=\mathrm{PNEC}_{\text {A.flos-aquae; }}$ Dotted orange line $=\mathrm{PNEC}_{\text {s. leopoldensis. }}$ 


\begin{tabular}{|c|c|c|c|c|c|}
\hline Antibiotic & $\begin{array}{l}\text { Protection } \\
\text { limit }\end{array}$ & $\begin{array}{c}\text { Concentration } \\
(\mu \mathrm{g} / \mathrm{L})\end{array}$ & Lower 95\% CI & Higher $95 \%$ CI & $\begin{array}{c}\text { Proportion of } \\
\text { cyanobacteria } \\
\text { affected (\%) }\end{array}$ \\
\hline \multirow{4}{*}{ Cefazolin } & HC5 & 1.13 & 0.13 & 19.88 & 5 \\
\hline & PNEC Lowest & 0.15 & - & - & 0.95 \\
\hline & $\mathrm{PNEC}_{\mathrm{A} \text {. flos-aquae }}$ & 0.15 & - & - & 0.95 \\
\hline & PNEC $_{\text {s. leopoldensis }}$ & 4.53 & - & - & 13.26 \\
\hline \multirow{4}{*}{ Cefotaxime } & HC5 & 0.67 & 0.32 & 1.13 & 5 \\
\hline & PNEC Lowest $_{\text {Le }}$ & 0.17 & - & - & 1.29 \\
\hline & $\mathrm{PNEC}_{\text {A. flos-aquae }}$ & 0.19 & - & - & 1.44 \\
\hline & PNEC $_{\text {s. leopoldensis }}$ & 0.7 & - & - & 5.2 \\
\hline \multirow{4}{*}{ Ampicillin } & HC5 & 8.56 & $0^{* *}$ & 26.47 & 5 \\
\hline & PNEC Lowest $_{\text {L }}$ & 0.49 & - & - & 0.91 \\
\hline & $\mathrm{PNEC}_{\mathrm{A} \text {. flos-aquae }}$ & 3 & - & - & 1.56 \\
\hline & PNEC $_{\text {s. leopoldensis }}$ & 1.15 & - & - & 1.05 \\
\hline \multirow{4}{*}{ Erythromycin } & HC5 & 21.3 & 16.18 & 28.76 & 5 \\
\hline & PNEC $_{\text {Lowest }}$ & $0.62 *$ & - & - & 0 \\
\hline & $\mathrm{PNEC}_{\text {A. flos-aquae }}$ & 2.9 & - & - & 0 \\
\hline & PNECs. leopoldensis & 3.1 & - & - & 0 \\
\hline \multirow{4}{*}{ Azithromycin } & HC5 & 3.15 & 2.11 & 5.03 & 5 \\
\hline & PNEC Lowest & $0.15^{*}$ & - & - & 0 \\
\hline & $\mathrm{PNEC}_{\mathrm{A} \text {. flos-aquae }}$ & 1.02 & - & - & 0 \\
\hline & $\mathrm{PNEC}_{\text {s. leopoldensis }}$ & 0.19 & - & - & 0 \\
\hline
\end{tabular}

555 Table 2. Protection limits; 5\% hazardous concentration (HC5) based upon a species sensitivity

556 distribution (SSD) using 10\% effective concentrations ( $\left(\mathrm{EC}_{10}\right)$, predicted no effect concentrations

557 (PNECs) and the proportion of cyanobacteria affected based upon the SSD. PNECs determined as

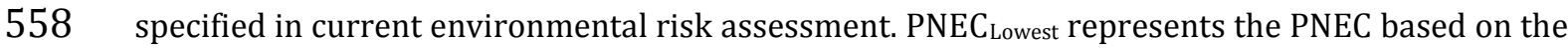

559 most sensitive cyanobacteria in the conducted assays. $\mathrm{PNEC}_{\mathrm{A} \text {. flos-aquae }}$ and $\mathrm{PNEC}_{\text {s. leopoldensis }}$ are

560 based on the data of species recommended in the OECD 201 test guideline (OECD, 2011).

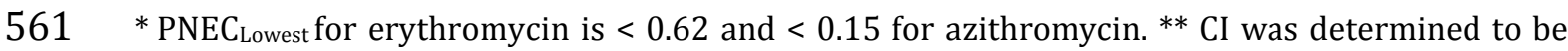
$562<0$. 


\begin{tabular}{|c|c|c|c|}
\hline \multirow{2}{*}{ Antibiotic } & $\begin{array}{c}\text { Measured } \\
\text { concentration }\end{array}$ & Concentration $(\boldsymbol{\mu g} / \mathbf{L})$ & $\begin{array}{c}\text { Proportion of } \\
\text { cyanobacteria } \\
\text { affected (\%) }\end{array}$ \\
\hline \multirow{2}{*}{ Cefazolin } & Median & $0.15(10)$ & 0.95 \\
\cline { 2 - 4 } & Highest & 42.9 (Lin et al., 2008) & 60 \\
\hline \multirow{2}{*}{ Cefotaxime } & Median & $0.033(16)$ & 0.25 \\
\cline { 2 - 4 } & Highest & 41.9 (Lin et al., 2008) & 96 \\
\hline \multirow{2}{*}{ Ampicillin } & Median & $0.021(15)$ & 0.85 \\
\cline { 2 - 4 } & Highest & 27.1 (Mutiyar and Mittal, 2013) & 44 \\
\hline \multirow{2}{*}{ Erythromycin } & Median & 0.050 (533) & 0 \\
\cline { 2 - 4 } & Highest & 7.8 (Lin and Tsai, 2009) & 0 \\
\hline \multirow{2}{*}{ Azithromycin } & Median & 0.054 (255) & 0 \\
\cline { 2 - 4 } & Highest & 2.8 (Jones-Lepp et al., 2012) & 3 \\
\hline
\end{tabular}

564 Table 3. Proportion (\%) of cyanobacteria affected at median and highest measured environmental concentrations (MECs) based on the cyanobacteria species sensitivity distributions using 10\%

566 effective concentrations and MECs obtained from Umweltbundesamt's 'Pharmaceuticals in the 567 environment' database (Umwelt bundesamt, 2018). Bracketed numbers indicate number of MECs 568 in median calculation.

\section{Discussion}

570 We show that for eight species of cyanobacteria the sensitivity for growth

571 inhibition for antibiotic exposure can vary widely and is influenced by the 572 antibiotic MoA. For the $\beta$-lactam antibiotics in particular, the interspecies 573 sensitivity varied by up to 70 times, far exceeding the AF of 10 currently applied 574 to the NOEC to establish the PNEC in ERA (based on a single species of 575 cyanobacteria). The SSD analysis indicated however that the current regulatory 576 approach to ERA in Europe was generally protective of $>98 \%$ of cyanobacteria 577 populations when the reference test species employed for this was A. flos-aque. 578 In contrast, the PNECs derived for cefazolin and cefotaxime when testing was 579 based upon S. leopoldensis (another OECD recommended species) would result in 580 growth inhibition for $13 \%$ and $5 \%$ of the tested cyanobacteria, respectively. In 
the case of macrolides, the SSDs showed that an AF of 10 might be at a level that

582 is suitable for the adequate population protection of cyanobacteria. We show

583 that in some of the more polluted environments with antibiotics, based on the

584 highest published MECs in the literature, up to $60 \%$ of cyanobacteria populations 585 may be affected in these specific environments.

\subsection{Chemical analysis, fate and behavior in the cultures}

587 Our analytical results showed considerable variation in the fate of the antibiotics 588 in our assays. Generally speaking, reductions in the measured concentrations 589 over the exposure period were high for the $\beta$-lactams, likely due to 590 photodegradation (Wang and Lin, 2012 \{Arsand, 2018 \#177), and for 591 azithromycin possibly due to adsorption to the culture vessel materials and 592 cellular or extracellular matter given its high partition-coefficient (LogP, 4.02) 593 and adsorption coefficient $\left(K_{d}, 3100\right)$ (National Center for Biotechnology 594 Information, 2018). Erythromycin and the sulfonamides were more stable in the 595 assay system.

597 Generally, the presence of the cyanobacteria resulted in a reduced amount of 598 antibiotic in the culture medium (measured at the end of the exposure) likely as 599 a consequence of adsorption and/or uptake into the bacterial cells and/or 600 biodegradation by the cyanobacteria. Biodegradation is considered the most 601 likely factor influencing the measured levels between the species studied for any 602 one antibiotic, particularly notable in the $\beta$-lactams, as differences in surface 603 binding of the antibiotic alone are very unlikely to account for this variation. 
604 Further discussion on the fate of the antibiotics tested in the assays can be found 605 in Supplementary material B.

\subsection{Cyanobacteria sensitivity}

$607 \boldsymbol{\beta}$-lactams: There was a major difference (up to 70 times) in sensitivity to $\beta$ 608 lactams (and in particular the cephalosporins) between the different species of 609 cyanobacteria in our study. The reason for this is unknown but it may reflect 610 differences in uptake rates caused by the quantity and type of porins in the outer 611 membrane (Li et al., 2015; Sugawara et al., 2016). The bilayered outer 612 membrane of cyanobacteria (and Gram-negative bacteria) is comprised of a 613 hydrophobic lipopolysaccharide and acts as an effective barrier to most drugs. 614 Antibiotics must therefore permeate through the membrane or use porin 615 channels to enter the periplasm. Porins tend to let small and non-lipophilic 616 molecules pass through with ease, which includes the $\beta$-lactams (as well as

617 fluoroquinolones, tetracycline, chloramphenicol, cycloserine, and 618 aminoglycosides antibiotics) (Delcour, 2009; Li et al., 2015). For the relatively 619 small molecules of cefazolin and ampicillin, we might thus expect that porin 620 channels to be the uptake main route. For the larger antibiotic cefotaxime 621 however, diffusion through the outer membrane may be more important in 622 cellular uptake as it may be too large to easily pass through porins. Indeed, the 623 susceptibility of the Gram-negative bacteria, K. pneumonia, was 4-8 times higher 624 to cefotaxime when the strain expressed a larger porin channel (García-Sureda et 625 al., 2011). 
627 Porins differ between bacterial clades and cyanobacteria specifically do not 628 appear to have the same porin families as those typically found in other bacteria 629 (Flores et al., 2006). Gram-negative bacteria, for example, generally have smaller 630 outer membrane porins but with higher channel conductance than cyanobacteria 631 allowing more molecules to enter into the cell (Hoiczyk and Hansel, 2000). It is 632 hypothesised that, as autotrophs, cyanobacteria synthesise the large organic 633 molecules they require (Hoiczyk and Hansel, 2000; Kowata et al., 2017), whilst 634 non-autotrophic bacteria need to uptake more (and larger) molecule types from 635 outside of the cell. It is therefore reasonable to hypothesise that cyanobacteria 636 may not be as susceptible as Gram-negative bacteria to larger antibiotics that 637 require larger porin channels. Since ERA only uses one species of cyanobacteria 638 to represent all primary producer diversity, if sensitivity is, at least in part, 639 driven by uptake due to their outer membrane porins, other bacterial clades 640 such as Gram-negative bacteria that differ in their membrane structure and 641 porins may not be well represented.

643 In addition to uptake, efflux and $\beta$-lactamase enzymes may have key roles in 644 determining the sensitivity of bacteria to antibiotics. Efflux rates of the 645 antibiotics in cyanobacteria studied are not known and thus conclusions cannot 646 be drawn, but our data do indicate the possibility of biodegradation for all the $\beta$ 647 lactams tested. For cefazolin this (potential) biodegradation was greatest for 648 S. elongates and Synechococcus sp., which were also the least sensitive species 649 tested based on growth inhibition. This is in accordance with findings that the 650 Gram-negative Enterobacteriaceae family showed interspecies variability in 651 sensitivity to $\beta$-lactams, ranging by between one and two orders of magnitude, 
652 which were attributed to differences in chromosomal $\beta$-lactamases (Stock, 653 2005).

654

655 Sulphonamides: Growth inhibition of cyanobacteria following exposure to 656 sulfonamides was generally limited and in some species the inhibitory effect 657 plateaued with increasing antibiotic concentration, which may suggest the 658 initiation of a possible resistance mechanism. The results are in accordance with 659 a recent meta-analysis where cyanobacteria were found to be less sensitive to 660 sulfonamides compared to microalgae and macrophytes (Le Page et al., 2017). A 661 possible explanation for their insensitivity could be that cyanobacteria contain a 662 protein (slr0642 identified in Synechocystis) that may act as a folate transporter 663 and which allows the uptake of folates from the environment. This in turn 664 overcomes the effect of the targeting of this drug on the folate synthesis pathway 665 (de Crécy-Lagard et al., 2007; Klaus et al., 2005). It should be highlighted that the 666 growth rate was lower than the controls and thus there appears to be some 667 fitness consequence to this resistance mechanism.

669 Macrolides: Responses to the macrolides were more consistent across the 670 cyanobacteria compared with the $\beta$-lactam antibiotics; the EC10s and EC50s for 671 the eight species differed by less than an order of magnitude. Uptake and efflux 672 may also influence the differences in cyanobacteria sensitivity to macrolides. 673 Indeed, (Stock, 2005) hypothesized that Gram-negative bacteria species specific 674 differences are, at least in part, driven by differences in outer membrane 675 hydrophobicity. Due to macrolides large size, uptake is generally thought to be 676 restricted by the outer membrane (Delcour, 2009; Stock, 2005), although there is 
677 some evidence that porin-like uptake may be present (Hahn et al., 2012). 678 Azithromycin is dicationic and less hydrophobic than erythromycin and may 679 therefore pass through the outer membrane more easily (Farmer et al., 1992; 680 Stock, 2005).

681

682 The similar levels of efficacy of the macrolides across the different cyanobacteria 683 species may, in part, be explained by the highly conserved ribosome drug target 684 (Lecompte et al., 2002; Yutin et al., 2012). R-proteins however, which make up 685 the ribosome, do vary between broader bacterial taxonomic clades and because 686 the MoA of macrolide antibiotics is highly dependent on the positioning and 687 interaction with the ribosome, differences in r-proteins between bacterial taxa 688 could feasibly affect antibiotic efficacy/action. Based on the literature, therefore, 689 the differences in cyanobacterial sensitivity to macrolides are more likely to 690 driven by differences in uptake or efflux than differences in the drug target given 691 that their ribosomes are likely evolutionarily well conserved. In addition to 692 decreased uptake/increased efflux, other mechanisms of resistance to 693 macrolides in Gram-negative bacteria comprise target mutations, methylation, 694 pseudouridylation and modification of the macrolide (Gomes et al., 2017), but 695 such resistance mechanisms have not yet been considered in cyanobacteria.

697 In our assays azithromycin had a greater potency than erythromycin across all 698 cyanobacteria species. Interestingly, azithromycin is reported to have modes of 699 action in addition to the ribosomal drug target that may help to explain this 700 enhanced potency. It is dicationic and it may disrupt the outer bacterial 701 membrane through the displacement of divalent cations from their binding sites 

724 There are limited published data available for sulfadiazine and sulfamethazine. 725 They are both veterinary antibiotics and so neither have EUCAST data and their

on adjacent lipopolysaccharide molecules in Gram-negative bacteria (Farmer et al., 1992; Imamura et al., 2005).

\subsection{Sensitivity comparisons with other bacteria}

Due to the limited data available for environmental bacteria we have compared the MIC for clinically relevant bacteria with the data obtained in our assays, but these values represent different parts of the dose-response curve the MIC represents the concentration with complete inhibition and the $\mathrm{EC}_{10}$ the concentration that inhibits growth rate by 10\%) (Bengtsson-Palme and Larsson, 2018; Le Page et al., 2018). Additionally, the EUCAST data is not based on measured concentrations and since the tests are conducted in the dark, we might thus expect less degradation via photolysis than observed in our assays.

When comparing the effects of $\beta$-lactams in this study with the MICs of clinically relevant bacteria in the EUCAST database, the most sensitive cyanobacteria in our study were 3-6 times more sensitive to cefozolin. In accordance with our hypothesis above that cyanobacteria may be less sensitive to the larger antibiotics as they do not have porins that enable their uptake, several of the clinically relevant bacteria appeared to be more sensitive to cefotaxime than cyanobacteria (EUCAST). The effects of ampicillin on the cyanobacteria were similar to those observed on cyanobacteria by (Ando et al., 2007) and within the ranges seen in clinically relevant bacteria in the EUCAST database (EUCAST). 
ecotoxicological profiles are rather poorly understood. Investigators have found

727 however that the MICs for sulfamethazine tend to be relatively high ( $>512 \mathrm{mg} / \mathrm{L}$

728 for both Gram-negative and Gram positive bacterial strains) compared with 729 other antibiotics (Salmon and Watts, 2000; Salmon et al., 1995).

730

731 Data on azithromycin is limited for ecotoxicologically relevant species but our 732 results are in accordance with those reported in (Vestel et al., 2015) where 733 cyanobacteria (species not provided) had a $\mathrm{EC}_{50}$ of $1.8 \mu \mathrm{g} / \mathrm{L}$. The MICs of 734 clinically relevant bacteria in the EUCAST database suggest that growth in the 735 most sensitive bacteria is inhibited completely at $16 \mu \mathrm{g} / \mathrm{L}$, which is consistent 736 with that for the more sensitive cyanobacteria in this study. For erythromycin, $737 \quad \mathrm{EC}_{50}$ S were generally similar to those obtained for eight species of cyanobacteria 738 by (Ando et al., 2007). They similarly found, $A$. cylindrical, to be the most 739 sensitive species but calculated the $\mathrm{EC}_{50}$ s to be over an order of magnitude lower 740 than in this study (3.5 compared to $44 \mu \mathrm{g} / \mathrm{L}$ respectively), albeit their tests 741 exposure period was twice that of in this study (6 days) (Ando et al., 2007)). The 742 most sensitive clinically relevant bacteria to erythromycin in the EUCAST 743 database have MICs from $8 \mu \mathrm{g} / \mathrm{L}$ (EUCAST), suggesting that for this antibiotic 744 that clinically relevant bacteria may be more sensitive than cyanobacteria.

\subsubsection{PNECs with an assessment factor of 10 are not always protective}

747 Our data suggest that for the $\beta$-lactams, depending on which species the PNEC

748 was derived from, protection of $>95 \%$ of cyanobacteria species was not be predicted by our SSDs, even with an assessment factor of 10 applied to account 
for such interspecies sensitivity differences. For the two macrolides however, the

751 PNEC was protective of all cyanobacteria regardless of the species from which

752 the PNEC was derived. These data indicate that under current ERA procedures

753 (of using a single test species) the choice of species is critical in establishing a

754 protection limit and the MoA can be an important factor in this consideration.

755 The large interspecies variability observed between cyanobacteria exposed to 756 cell membrane synthesis inhibitors causes the PNEC to have a higher probability 757 of being under protective because the assessment factor of 10 is likely 758 inadequate as highlighted in our previous meta-analysis (Le Page et al., 2017). 759 For other MoAs, such as the macrolides, the smaller interspecies variability 760 means an assessment factor of 10 is sufficient to cover the entire SSD no matter 761 which species is selected on which to base the PNEC.

762 The limited sensitivity of cyanobacteria to sulfonamide antibiotics confirmed the 763 findings from the previous meta-analysis (Le Page et al., 2017) expressing 764 concern that cyanobacteria may not be suitable for the estimation of 765 environmental protection limits. Furthermore, in some cases microalgae and 766 macrophytes may be more sensitive than cyanobacteria to this class of 767 antibiotics (Le Page et al., 2017) but under current ERA framework for 768 pharmaceuticals neither microalgae nor macrophytes would be tested, although 769 the revised ERA currently under consultation for the European Medicine Agency 770 does require a microalgae in addition to two cyanobacteria species and an 771 invertebrate (EMA, 2018). 
775 Results from this analysis suggest that an approach using a SSD with eight cyanobacteria to derive an HC5 or $\mathrm{HC}_{(2.5)}$ with a small assessment factor (of less than 10) may be more suitable for the determination of protection limits for cyanobacteria populations than the traditional PNEC. But additional testing on other bacterial classes is required to ensure protection of bacteria more generally. We emphasise that a PNEC based on the NOEC and AF of 10 was generally adequately protective providing the species on which it was based was 782 sensitive. If we consider the two species recommended in the OECD 201 test 783 guideline, a PNEC based upon A. flos-aquae was protective but a PNEC based 784 upon S. leopoldensis was under protective for both cefazolin and cefotaxime. 785 Furthermore, for some MoAs such as sulphonamides, its possible that a PNEC 786 using an AF of 10 will be under protective of bacteria more generally regardless 787 of which cyanobacteria species is used.

788 For the cephalosporins, the HC5 was generally 4 - 8 times higher than the

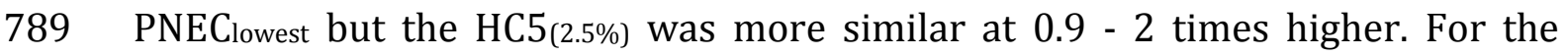
790 macrolides the HC5 far exceeded this and was up to 34 times higher than the 791 PNEClowest, further highlighting how the PNEC and assessment factor of 10 might 792 be highly conservative as a protective factor for this antibiotic class/MoA. These 793 results therefore support the suggestion that the $\operatorname{HC5}(2.5 \%)$ could be used to 794 ensure an empirically based protection limit that is a more accurate and is 795 protective of $95 \%$ of cyanobacteria (Wheeler et al., 2002) without being over 796 protective in for some MoAs as appears to be the case for the PNECs for 
macrolides. The HC5 95\% confidence intervals suggest some uncertainty

798 (although this is relatively small) but given that these estimates incorporate the 799 error around the original $\mathrm{EC}_{10 \mathrm{~s}}$ via the use of the $95 \%$ confidence limits as 800 censored data, this might be expected. The wider HC5 95\% confidence limits for 801 cefazolin may be due to higher variability observed between replicates in the 802 microplate assay.

803 The HC5 has been suggested as a protection limit under the premise that 804 functional redundancy (where multiple species are capable of performing the 805 same ecological functions) in the ecosystem will compensate for some small 806 effects on the most sensitive species (Solomon and Sibley, 2002). However, the 807 magnitude of functional redundancy is not clear, especially in bacterial 808 communities (Antwis et al., 2017). Further investigation is required to explore 809 the hypothesis that $5 \%$ of species can be affected beyond their $\mathrm{EC}_{10}$ without 810 adverse effects upon environmental communities and ecosystem function. Such 811 studies are best undertaken using semi-field test designs, as conducted, for 812 example, by (Rico et al., 2014). These authors found disruptions to the nitrogen 813 cycle occurred in mesocoms exposed to enrofloxacin that resulted from reduced 814 numbers of ammonia-oxidising bacteria and archaea leading to higher ammonia 815 and lower nitrate concentrations. In order to better estimate the effects of 816 antibiotics on ecosystem functioning, additional endpoints that better represent 817 functions of interest might usefully be included, for example oxygen evolution 818 (as a proxy for photosynthetic rate) and pigment content (Guo et al., 2016b).

819 The selection of species for use in an SSD is important (Verdonck et al., 2003). 820 Our analysis reflects only cyanobacteria sensitivity, and even here we studied 
821 only a small selection of classes of cyanobacteria that grew adequately in the 822 assay method adopted. Thus, a more diverse range of bacteria should be 823 included since sensitivity differences between taxonomic clades could be large, 824 even spanning several orders of magnitude. Furthermore, it should be 825 emphasised that non-bacterial taxa including certain macrophytes (Le Page et al., 826 2017) and diatoms (Guo et al., 2016a) have been shown to be more sensitive to 827 some antibiotics (e.g. sulphonamides and trimethoprim) than cyanobacteria. It is 828 likely that some other bacterial taxa (i.e. not cyanobacteria) could be equally or 829 more sensitive than all eukaryotes and thus it should be possible to select an 830 appropriate diversity of bacteria for ERA testing of antibiotics that provide 831 appropriate limits for the protection of all prokaryotes and eukaryotes.

832 A protection limit also needs to consider the extrapolation from the laboratory to 833 the field. Previous authors have concluded that large safety factors are not 834 considered necessary for extrapolation between the laboratory and field 835 (Chapman et al., 1998). Indeed, biofilms in the field may provide resilience to 836 chemical toxicity due to the protective nature of complex biofilm communities 837 and extracellular substances (Harrison et al., 2007) and interspecies competition 838 for resources may lower sensitivity to chemical contaminants (Rico et al., 2018). 839 On the other hand, environmental conditions could significantly increase the 840 sensitivity of bacteria to antibiotics due to chemical mixtures or as a result of 841 different biotic and abiotic factors (e.g. competition, predation, temperature, $\mathrm{pH}$ 842 (Rohr et al., 2016)). As such, in the absence of conclusive evidence 843 demonstrating the safe concentrations in mixtures or in a variety of 844 environmental conditions, it may be prudent to take a protective approach and 
845 continue to include an assessment factor to compensate for this, as is required in 846 some regulatory guidance (EFSA, 2013; TGD, 2003). Using an assessment factor 847 with the HC5 or HC5(2.5) to establish a protection limit may appear to undermine 848 the benefits of conducting a more accurate, reliable and robust SSD but more 849 confidence can be applied to an empirically derived $\mathrm{HC} 5 / \mathrm{HC}{ }_{(2.5)}$ with a smaller 850 assessment factor (of less than 10, although further investigation is required as 851 these are still largely arbitrary) and for which error can be quantified. 852 Furthermore, a HC5 has greater certainty compared with the current PNEC and 853 thus a reduced likelihood of underestimating the PNEC where interspecies 854 variability is high and overestimating the PNEC where interspecies variability is 855 low. Finally, a SSD based on an $\mathrm{EC}_{\mathrm{x}}$ avoids the criticisms of the NOEC that is 856 flawed and dependent of experimental design.

857 The SSDs highlight that for the majority of MECs there is a limited general effect 858 on cyanobacteria in the natural systems (potentially affected proportions of $859<1 \%$ ) from all antibiotics based on the median MEC, which was based on data 860 where the non-detects were excluded and thus a worse case scenario. However, 86160,96 and $44 \%$ of cyanobacteria may be affected when exposed to the highest 862 cefazolin, cefotaxime and ampicillin environmentally relevant MECs recorded in 863 the UBA database (Umwelt bundesamt, 2018). Our analysis therefore suggests 864 that there are some cyanobacterial communities that may be severely affected by 865 antibiotic pollution with potential consequences on the ecosystem functions that 866 they provide. Equally, however, our data suggests that these effects are likely to 867 be restricted to a small number of highly contaminated locations. In order to 868 better estimate the risk of antibiotics in the environment, there is an urgent need 
869 for more quantitative data on antibiotics in freshwater systems allowing for a

870 better understanding of the distribution of MECs and more accurate estimations

871 on possible associated risks.

872 Our results also show that a more comprehensive understanding of the effects of

873 antibiotics upon prokaryotic diversity is needed for appropriate environmental

874 protection. We argue that an ERA should include consideration of microbes that

875 are known to play key roles in ecosystems function/services, such as nitrifying

876 bacteria or sulphate-reducing bacteria as some of the organisms we may wish

877 most to protect. Additionally, the effects on community structure and diversity

878 should also be considered given that if a specific group of bacteria in a

879 community increased or decreased in abundance due to antibiotic exposure,

880 there may be significant consequences for the normal functioning of that 881 community.

\section{Conclusions}

883 In this study we have used a microplate assay to assess the relative interspecies 884 sensitivity of a range of cyanobacteria to the effects of seven antibiotics spanning 885 three general MoAs. Our experimental data verify the findings of a meta-analysis 886 of published literature (Le Page et al., 2017) where large interspecies sensitivity 887 is observed and is influenced by the MoA. To our knowledge, we present the first 888 environmentally relevant bacterial data for cefazolin and sulfamethazine. 889 Although a PNEC established using an assessment factor of 10 on a NOEC 890 appears to generally be protective when a sensitive species for that antibiotic is 891 tested, it may cause protection limits to be either over- or under-protective 
892

893

894

895

896

897

898

899

900

901

902 Page et al., 2017)). Finally, we show that the highest recorded MECs in the

903 literature may pose a significant threat to cyanobacteria populations.

\section{$904 \quad$ Funding}

905 This work was supported by the AstraZeneca Global SHE Research ProGramme

906 (047944). KCAW is funded by the MRC Fellowship (MR/P01478X/1).

\section{Competing financial interests declaration:}

908 GLP is a former employee and current shareholder of AstraZeneca PLC. JRS is an 909 employee and shareholder of AstraZeneca PLC.

\section{Acknowledgements}

911 We would like to thank Sandrine Charles for her assistance in establishing data

912 handling rules and dose-response modelling. We also thank Eduard Szocs for

913 assistance in constructing the SSD graphics (https://edild.github.io/ssd/). 
914

915

916

917

918

919

920

921

922

923

924

925

926

927

928

929

930

931

932

933

934

935

936

937

938

939

940

941

942

943

944

945

946

947

948

949

950

951

952

953

954

955

956

957

958

\section{References}

Agerstrand M, Berg C, Bjorlenius B, Breitholtz M, Brunstrom B, Fick J, et al. Improving Environmental Risk Assessment of Human Pharmaceuticals. Environmental Science \& Technology 2015; 49: 5336-5345.

Aldenberg T, Jaworska JS, Traas TP. Normal species sensitivity distributions and probabilistic ecological risk assessment. Species sensitivity distributions in ecotoxicology. CRC Press, 2001, pp. 73-126.

Ando T, Nagase H, Eguchi K, Hirooka T, Nakamura T, Miyamoto K, et al. A novel method using cyanobacteria for ecotoxicity test of veterinary antimicrobial agents. Environmental Toxicology and Chemistry 2007; 26: 601-606.

Antwis RE, Griffiths SM, Harrison XA, Aranega-Bou P, Arce A, Bettridge AS, et al. Fifty important research questions in microbial ecology. FEMS Microbiology Ecology 2017; 93: fix044-fix044.

Batt AL, Kim S, Aga DS. Comparison of the occurrence of antibiotics in four fullscale wastewater treatment plants with varying designs and operations. Chemosphere 2007; 68: 428-435.

Belanger S, Barron M, Craig P, Dyer S, Galay-Burgos M, Hamer M, et al. Future needs and recommendations in the development of species sensitivity distributions: Estimating toxicity thresholds for aquatic ecological communities and assessing impacts of chemical exposures. Integrated Environmental Assessment and Management 2017; 13: 664-674.

Bengtsson-Palme J, Larsson DGJ. Protection goals must guide risk assessment for antibiotics. Environment International 2018; 111: 352-353.

Brandt KK, Amézquita A, Backhaus T, Boxall A, Coors A, Heberer T, et al. Ecotoxicological assessment of antibiotics: A call for improved consideration of microorganisms. Environment International 2015; 85: 189-205.

Brown KD, Kulis J, Thomson B, Chapman TH, Mawhinney DB. Occurrence of antibiotics in hospital, residential, and dairy effluent, municipal wastewater, and the Rio Grande in New Mexico. Science of The Total Environment 2006; 366: 772-783.

Cabello FC. Heavy use of prophylactic antibiotics in aquaculture: a growing problem for human and animal health and for the environment. Environmental Microbiology 2006; 8: 1137-1144.

Carvalho R, Ceriani L, Ippolito A, Lettieri T. Development of the First Watch List Under the Environmental Quality Standards Directive. Directive 2008/105/EC, as Amended by Directive 2013/39/EU, in the Field of Water Policy. Joint Technical Report EUR 27142 EN, 2015.

Chapman PM, Fairbrother A, Brown D. A critical evaluation of safety (uncertainty) factors for ecological risk assessment. Environmental Toxicology and Chemistry 1998; 17: 99-108.

Chen Y, Zhang H, Luo Y, Song J. Occurrence and dissipation of veterinary antibiotics in two typical swine wastewater treatment systems in east China. Environmental Monitoring and Assessment 2012; 184: 2205-2217. 
de Crécy-Lagard V, El Yacoubi B, de la Garza RD, Noiriel A, Hanson AD. Comparative genomics of bacterial and plant folate synthesis and salvage: predictions and validations. BMC Genomics 2007; 8: 245.

Delcour AH. Outer membrane permeability and antibiotic resistance. Biochimica et Biophysica Acta (BBA) - Proteins and Proteomics 2009; 1794: 808-816.

Delignette-Muller ML, Dutang C. fitdistrplus: An R package for fitting distributions. Journal of Statistical Software 2015; 64: 1-34.

Dopheide A, Lear G, He Z, Zhou J, Lewis GD. Functional Gene Composition, Diversity and Redundancy in Microbial Stream Biofilm Communities. PLOS ONE 2015; 10: e0123179.

EC. Directive 2001/83/EC of the European Parliament and of the Council of 6 November 2001 on the Community code relating to medicinal products for human use. In: European Union, editor, Brussels, Belgium, 2001.

EFSA. Guidance on tiered risk assessment for plant protection products for aquatic organisms in edge-of-field surface waters. EFSA Journal 2013; 11: 3290.

EMA. GUIDELINE ON THE ENVIRONMENTAL RISK ASSESSMENT OF MEDICINAL PRODUCTS FOR HUMAN USE. EMEA/CHMP/SWP/4447/00 Rev. 1, 2018.

Environment Canada. Biological Test Method: Growth Inhibition Test Using a Freshwater Alga. Series, Environmental Protection 2007.

EUCAST. Data from the European Committee on Antimicrobial Susceptibility Testing, MIC distribution website. 2018.

European Commission Joint Research Centre. Technical Guidance Document on Risk Assessment in Support of Commission Directive 93/67/EEC on Risk Assessment for New Notified Substances and Commission Regulation (EC) No 1488/94 on Risk Assessment for Existing Substances and Directive 98/8/EC of the European Parliament and the Council Concerning the placing of biocidal products on the market. Part II. , 2003. Falkowski PG. Evolution of the nitrogen cycle and its influence on the biological sequestration of CO2 in the ocean. Nature 1997; 387: 272.

Farmer S, Li Z, Hancock RE. Influence of outer membrane mutations on susceptibility of Escherichia coli to the dibasic macrolide azithromycin. Journal of Antimicrobial Chemotherapy 1992; 29: 27-33.

Flores E, Herrero A, Wolk CP, Maldener I. Is the periplasm continuous in filamentous multicellular cyanobacteria? Trends in Microbiology 2006; 14: 439-443.

Forbes VE, Calow P. Species sensitivity distributions revisited: a critical appraisal. Human and Ecological Risk Assessment: An International Journal 2002; 8: 473-492.

García-Sureda L, Juan C, Doménech-Sánchez A, Albertí S. Role of Klebsiella pneumoniae LamB porin in antimicrobial resistance. Antimicrobial Agents and Chemotherapy 2011.

Gomes C, Martínez-Puchol S, Palma N, Horna G, Ruiz-Roldán L, Pons MJ, et al. Macrolide resistance mechanisms in Enterobacteriaceae: Focus on azithromycin. Critical Reviews in Microbiology 2017; 43: 1-30.

Green JW, Springer TA, Staveley JP. The drive to ban the NOEC/LOEC in favor of ECx is misguided and misinformed. Integrated Environmental Assessment and Management 2013; 9: 12-16. 
Grenni P, Ancona V, Barra Caracciolo A. Ecological effects of antibiotics on natural ecosystems: A review. Microchemical Journal 2018; 136: 25-39.

Guo J, Selby K, Boxall A. Comparing the sensitivity of chlorophytes, cyanobacteria and diatoms to major-use antibiotics. Environmental Toxicology and Chemistry 2016a: n/a-n/a.

Guo J, Selby K, Boxall ABA. Effects of Antibiotics on the Growth and Physiology of Chlorophytes, Cyanobacteria, and a Diatom. Archives of environmental contamination and toxicology 2016b; 71: 589-602.

Hahn A, Stevanovic M, Mirus O, Schleiff E. The TolC-like protein HgdD of the cyanobacterium Anabaena sp. PCC 7120 is involved in secondary metabolite export and antibiotic resistance. Journal of Biological Chemistry 2012.

Harrison JJ, Ceri H, Turner RJ. Multimetal resistance and tolerance in microbial biofilms. Nature Reviews Microbiology 2007; 5: 928.

Hoiczyk E, Hansel A. Cyanobacterial Cell Walls: News from an Unusual Prokaryotic Envelope. Journal of Bacteriology 2000; 182: 1191-1199.

Imamura Y, Higashiyama Y, Tomono K, Izumikawa K, Yanagihara K, Ohno H, et al. Azithromycin Exhibits Bactericidal Effects on <em $>$ Pseudomonas aeruginosa $</$ em $>$ through Interaction with the Outer Membrane. Antimicrobial Agents and Chemotherapy 2005; 49: 1377-1380.

Jaimes-Correa JC, Snow DD, Bartelt-Hunt SL. Seasonal occurrence of antibiotics and a beta agonist in an agriculturally-intensive watershed. Environmental Pollution 2015; 205: 87-96.

Jones-Lepp TL, Sanchez C, Alvarez DA, Wilson DC, Taniguchi-Fu R-L. Point sources of emerging contaminants along the Colorado River Basin: Source water for the arid Southwestern United States. Science of The Total Environment 2012; 430: 237-245.

Klaus SM, Kunji ER, Bozzo GG, Noiriel A, de La Garza RD, Basset GJ, et al. Higher plant plastids and cyanobacteria have folate carriers related to those of trypanosomatids. Journal of Biological Chemistry 2005.

Kon Kam King G, Delignette-Muller ML, Kefford BJ, Piscart C, Charles S. Constructing time-resolved species sensitivity distributions using a hierarchical toxico-dynamic model. Environmental science \& technology 2015; 49: 12465-12473.

Kon Kam King G, Veber P, Charles S, Delignette - Muller ML. MOSAIC_SSD: A new web tool for species sensitivity distribution to include censored data by maximum likelihood. Environmental toxicology and chemistry 2014; 33: 2133-2139.

Kowata H, Tochigi S, Takahashi H, Kojima S. Outer Membrane Permeability of Cyanobacterium Synechocystis sp. Strain PCC 6803: Studies of Passive Diffusion of Small Organic Nutrients Reveal the Absence of Classical Porins and Intrinsically Low Permeability. Journal of Bacteriology 2017; 199: e00371-17.

Kümmerer K. Antibiotics in the aquatic environment - A review - Part I. Chemosphere 2009; 75: 417-434.

Larsson DGJ. Pollution from drug manufacturing: review and perspectives. Philosophical Transactions of the Royal Society B: Biological Sciences 2014; 369. 
Larsson DGJ, de Pedro C, Paxeus N. Effluent from drug manufactures contains extremely high levels of pharmaceuticals. Journal of Hazardous Materials 2007; 148: 751-755.

Le Page G, Gunnarsson L, Snape J, Tyler CR. Integrating human and environmental health in antibiotic risk assessment: A critical analysis of protection goals, species sensitivity and antimicrobial resistance. Environment International 2017; 109: 155-169.

Le Page G, Gunnarsson L, Snape J, Tyler CR. Antibiotic risk assessment needs to protect both environmental and human health. Environment International 2018; 115: 397-399.

Le Page G, Gunnarsson L, Snape J, Tyler CR. Development and application of a microplate assay for toxicity testing on aquatic cyanobacteria. Under submission.

Lecompte O, Ripp R, Thierry J-C, Moras D, Poch O. Comparative analysis of ribosomal proteins in complete genomes: an example of reductive evolution at the domain scale. Nucleic Acids Research 2002; 30: 53825390.

Li D, Yang M, Hu J, Ren L, Zhang Y, Li K. Determination and fate of oxytetracycline and related compounds in oxytetracycline production wastewater and the receiving river. Environmental Toxicology and Chemistry 2008; 27: 8086.

Li X-Z, Plésiat P, Nikaido H. The Challenge of Efflux-Mediated Antibiotic Resistance in Gram-Negative Bacteria. Clinical Microbiology Reviews 2015; 28: 337-418.

Lin AY-C, Tsai Y-T. Occurrence of pharmaceuticals in Taiwan's surface waters: Impact of waste streams from hospitals and pharmaceutical production facilities. Science of The Total Environment 2009; 407: 3793-3802.

Lin AY-C, Yu T-H, Lin C-F. Pharmaceutical contamination in residential, industrial, and agricultural waste streams: Risk to aqueous environments in Taiwan. Chemosphere 2008; 74: 131-141.

Liu X, Steele JC, Meng X-Z. Usage, residue, and human health risk of antibiotics in Chinese aquaculture: a review. Environmental pollution 2017; 223: 161169.

Loos R, Marinov D, Sanseverino I, Napierska D, Lettieri T. Review of the 1st Watch List under the Water Framework Directive and recommendations for the 2nd Watch List. 2018. Publications Office of the European Union: Pages 1 - 267.

Mutiyar PK, Mittal AK. Occurrences and fate of an antibiotic amoxicillin in extended aeration-based sewage treatment plant in Delhi, India: a case study of emerging pollutant. Desalination and Water Treatment 2013; 51: 6158-6164.

National Center for Biotechnology Information. PubChem Compound Database,. August 2018, 2018.

OECD. Test No. 201: Freshwater Alga and Cyanobacteria, Growth Inhibition Test, OECD Guidelines for the Testing of Chemicals, Section 2. OECD Publishing, Paris, 2011.

Rico A, Dimitrov MR, Van Wijngaarden RPA, Satapornvanit K, Smidt H, Van den Brink PJ. Effects of the antibiotic enrofloxacin on the ecology of tropical eutrophic freshwater microcosms. Aquatic Toxicology 2014; 147: 92-104. 
Rico A, Zhao W, Gillissen F, Lürling M, Van den Brink PJ. Effects of temperature, genetic variation and species competition on the sensitivity of algae populations to the antibiotic enrofloxacin. Ecotoxicology and Environmental Safety 2018; 148: 228-236.

Rippka R, Deruelles J, Waterbury JB, Herdman M, Stanier RY. Generic assignments, strain histories and properties of pure cultures of cyanobacteria. Microbiology 1979; 111: 1-61.

Ritz C, Baty F, Streibig JC, Gerhard D. Dose-Response Analysis Using R. PLOS ONE 2015; 10.

Rohr JR, Salice CJ, Nisbet RM. The pros and cons of ecological risk assessment based on data from different levels of biological organization. Critical Reviews in Toxicology 2016; 46: 756-784.

Salmon SA, Watts JL. Minimum Inhibitory Concentration Determinations for Various Antimicrobial Agents against 1570 Bacterial Isolates from Turkey Poults. Avian Diseases 2000; 44: 85-98.

Salmon SA, Watts JL, Case CA, Hoffman LJ, Wegener HC, Yancey RJ. Comparison of MICs of ceftiofur and other antimicrobial agents against bacterial pathogens of swine from the United States, Canada, and Denmark. Journal of Clinical Microbiology 1995; 33: 2435-2444.

Schmitt-Jansen M, Veit U, Dudel G, Altenburger R. An ecological perspective in aquatic ecotoxicology: Approaches and challenges. Basic and Applied Ecology 2008; 9: 337-345.

Segner H. Moving beyond a descriptive aquatic toxicology: The value of biological process and trait information. Aquatic Toxicology 2011; 105: 50-55.

Shih PM, Wu D, Latifi A, Axen SD, Fewer DP, Talla E, et al. Improving the coverage of the cyanobacterial phylum using diversity-driven genome sequencing. Proceedings of the National Academy of Sciences 2013; 110: 1053-1058.

Sim W-J, Lee J-W, Lee E-S, Shin S-K, Hwang S-R, Oh J-E. Occurrence and distribution of pharmaceuticals in wastewater from households, livestock farms, hospitals and pharmaceutical manufactures. Chemosphere 2011; 82: 179-186.

Solomon KR, Sibley P. New concepts in ecological risk assessment: where do we go from here? Marine Pollution Bulletin 2002; 44: 279-285.

Stock I. Natural antimicrobial susceptibility patterns of Kluyvera ascorbata and Kluyvera cryocrescens strains and review of the clinical efficacy of antimicrobial agents used for the treatment of Kluyvera infections. Journal of chemotherapy $2005 ; 17: 143-160$.

Sugawara E, Kojima S, Nikaido H. Klebsiella pneumoniae Major Porins OmpK35 and OmpK36 Allow More Efficient Diffusion of $\beta$-Lactams than Their Escherichia coli Homologs OmpF and OmpC. Journal of Bacteriology 2016; 198: 3200-3208.

TGD E. Technical guidance document on risk assessment in support of commission directive 93/67/EEC on risk assessment for new notified substances, Commission Regulation (EC) No 1488/94 on Risk Assessment for existing substances, and Directive 98/8/EC of the European Parliament and of the Council concerning the placing of biocidal products on the market. Part I-IV, European Chemicals Bureau (ECB), JRC-Ispra (VA), Italy, April 2003. Part II. European Commission Joint Research Centre. EUR 2003; 20418. 
Umwelt bundesamt. Database - Pharmaceuticals in the environment, https://www.umweltbundesamt.de/en/database-pharmaceuticals-inthe-environment-1, 2018.

US EPA. 74 FR 51850 Drinking water contaminant candidate List 3, 2009.

Verdonck FAM, Aldenberg T, Jaworska J, Vanrolleghem PA. Limitations of current risk characterization methods in probabilistic environmental risk assessment. Environmental Toxicology and Chemistry 2003; 22: 22092213.

Verdonck FAM, Jaworska J, Thas O, Vanrolleghem PA. Determining environmental standards using bootstrapping, bayesian and maximum likelihood techniques: a comparative study. Analytica Chimica Acta 2001; 446: 427-436.

Vestel J, Caldwell DJ, Constantine L, D'Aco VJ, Davidson T, Dolan DG, et al. Use of acute and chronic ecotoxicity data in environmental risk assessment of pharmaceuticals. Environmental Toxicology and Chemistry 2015: n/an/a.

Wang X-H, Lin AY-C. Phototransformation of Cephalosporin Antibiotics in an Aqueous Environment Results in Higher Toxicity. Environmental Science \& Technology 2012; 46: 12417-12426.

Watkinson AJ, Murby EJ, Kolpin DW, Costanzo SD. The occurrence of antibiotics in an urban watershed: From wastewater to drinking water. Science of The Total Environment 2009; 407: 2711-2723.

Wheeler JR, Grist EPM, Leung KMY, Morritt D, Crane M. Species sensitivity distributions: data and model choice. Marine Pollution Bulletin 2002; 45: 192-202.

Yutin N, Puigbò P, Koonin EV, Wolf YI. Phylogenomics of Prokaryotic Ribosomal Proteins. PLOS ONE 2012; 7: e36972. 